\title{
6 Kirchenschatz und indulgentiae
}

In der Stichserie des polnischen Kanonikers Tomasz Treter und des Trienter Kupferstechers Giovanni Battista de' Cavalieri wurde ein Bild der Ecclesia vorgelegt, das mit den urbanen Bedingungen Roms zur Ausgestaltung des sacerdotium und sacrificium Christi übereinstimmte. Das Priestertum erschien damit als sichtbare Verkörperung des Kreuzes- und Messopfers und verkörperte dementsprechend das Heilsversprechen selbst. Dem priesterlichen Vollzug der sakramentalen Verwaltungspraxis wurde somit eine bislang von der Forschung noch kaum beachtete Bedeutung verliehen. Dieser neue Stellenwert des Priestertums lag auch der neuen Gestalt des sich im rituellen Vollzug sichtbar ausführenden Kurienzeremoniells zu Grunde. Das Kurienzeremoniell sollte dadurch einem Wandel unterzogen werden, um essentielle Bezüge zu dem sich sichtbar vollziehenden sacerdotium herstellen zu können. Die bruderschaftlichen Werke der caritas bildeten somit den wichtigsten Bestandteil der zeremoniell-sichtbaren Entfaltung der caritas im Rom des anno santo. Aus diesen Werken der bruderschaftlichen Nächstenliebe liess sich nämlich der wichtige Stellenwert der Verehrung der Eucharistie ableiten. In diese wichtige Verehrungspraxis reihte sich auch Filippo Neris Oratorium ein. ${ }^{651}$ Die der Heiligen Eucharistie dargebotene Andacht erreichte im Kurienzeremoniell bei der jährlich stattfindenden Prozession zum Fronleichnamsfest ihren Höhepunkt. Im Jubeljahr erfuhr dieses Zeremoniell des Corpus Domini die wichtigste Veränderung. Daher ist diese zeremonielle Feier als Produkt eins neuen Verständnisses darüber, wie die göttliche Gnade zu verwalten ist, zu verstehen. Dieses Neuverständnis des göttlichen Gnadenerweises bildete die theologische Grundlage der am 10. Mai 1574 erlassenen Papstbulle Gregors XIII., De thesauro meritorum Ecclesiae. Im Folgenden soll daher zuerst die Aktualisierung einer mittelalterlichen Schatztheologie erklärt werden, um danach erläutern zu können, wie das Kurienzeremoniell während des Jubeljahres an die im Stadtraum stattfindenden Feiern angepasst wurde. Bei der Ausgestaltung des Kurienzeremoniells war es demnach von zentraler Bedeutung, aufzuzeigen, wie das Zeremoniell mit der Einteilung des städtischen Heilsraumes verbunden war. Die päpstliche Anerkennung von Filippo Neris Oratorium als Priesterkongregation schuf einen wichtigen Standort innerhalb dieser neuen Stadt- und Heilsordnung Roms. Cesare Baronios frühe Anstrengungen, der Kongregation mittels spezifischer officia einen institutionellen Charakter zu verleihen, wurden vom kurialen Umfeld der kirchenhistoriographischen Widerlegungsarbeiten gegen die protestantische Theologie aufgenommen.

651 Martin, Roma Sancta, S. 209-210, der das sodalitium als "Compagnie of the Oratorie“ bezeichnet.

Ә Open Access. () 2022 Filip Malesevic, publiziert von De Gruyter. (c) BY-NC-ND Dieses Werk ist lizenziert unter einer Creative Commons Namensnennung - Nicht-kommerziell - Keine Bearbeitung 4.0 International Lizenz. https://doi.org/10.1515/9783110741117-007 


\subsection{Die Neuauslegung der mittelalterlichen Schatztheologie}

Das Zeremoniell der Öffnung der Porta Santa nahm als offizielle Eröffnung des Jubeljahres die theologische Bedeutung der menschlichen Teilnahme an der misericordia Dei vorweg. Jeder Gläubige musste sich aber diese Barmherzigkeit im Jubeljahr zuerst verdienen. Die Grundlage dieser verdienten Sündenvergebung schuf die am 10. Mai 1574 erlassene Papstbulle Gregors XIII. Ihr Text bezog sich auf die bereits für das erste Heilige Jahr 1300 zentrale Schatztheologie und benutzte diese, um die wichtige Frage zu beantworten, wie diese menschliche Teilnahme am göttlichen Gnadenschatz neu zu gestalten sei. Dabei nahm sich die Bulle das ambrosianische Verständnis der Ecclesia sponsae Christi zum Vorbild. Daraus liess sich nämlich die in der potestas papalis begründete Kraft der göttlichen Gnade, die jeder Papst als Praepositus Ecclesiae in der Nachfolge des Apostelfürsten Petrus besass und spenden konnte, ableiten. ${ }^{652}$

Aus den Einträgen im Tagebuch des Zeremonienmeisters Francesco Mucanzio kann nachgewiesen werden, dass die Papstbulle am 20. Mai 1574 feierlich in der Petersbasilika verkündet wurde. Als ihr Verfasser gilt der damalige Brevensekretär Cesare Gloriero, der die Bulle zu Füssen (ante pedes) des Boncompagni-Papstes niederlegte, bevor dieser den Kirchenraum durch den Haupteingang (Portam maiorem) betrat. Nach dem Eintritt in die Petersbasilika legte Gregor XIII. die Bulle auf den Sakramentsaltar nieder und las den Text alta voce vor. Daran schloss sich die offizielle Publikation der Papstbulle an. ${ }^{653}$ Bis zum Zeitpunkt, als der Borghese-Papst Paul V. alle Altäre der Petersbasilika neu weihte, befand sich der Sakramentsaltar in der Cappella dei Santi Simone e Giudea im südlichen Querhausarm. Die überlieferte Zeichnung in Giacomo Grimaldis Album aus dem Kapitulararchiv der Petersbasilika zeigt das äussere Ornat der Kapelle nach 1548. ${ }^{654}$ Mucanzio erwähnt in seinem Tagebuch die für die Ausstattung der Petersbasilika getroffenen Vorbereitungen zum Anlass

652 Der Text der Bulle findet sich abgedruckt in Schmidt, Bullarium, S. 70-72, hier 70-71: Dominus ac Redemptor noster Iesus Christus, qui pro ineffabili caritate sua servi formam accipiens, acerbissimam crucis mortem subire dignatus est, ut Deo Patri genus humanum reconciliaret atque in sortem hereditatis aeternae vocaret, volens nostrae plenius succurrere imbecillitati, et donum hoc pretiosissimo ipsius sanguine acquisitum copiosus communicare, ne lapsis post regenerationis lavacrum opportunum eiusdem divinae misericordiae deesset subsidium, beato Petro apostolorum Principi eiusque deinceps successoribus suis in terris Vicariis Sanctae Catholicae Romanae Praepositis Ecclesiae [...] potestatem dimittendi peccata plenissimam reliquit, ac thesauro praeterea immenso meritorum eiusdem passionis (cui etiam gloriosissimae semper Virginis Mariae omniumque sanctorum merita accedunt) idcirco ditavit ecclesiam sponsam suam, eumque praedictis beato Petro et successoribus dispensandum commisit, ut eo ceteri fideles pro temporalibus poenis ex remissis culpis saepius remanentibus ad satisfaciendum adiuti ad percipiendos coelestis gratiae fructus expeditores redderentur.

653 BAV, Chig.L.II.30, f. 215v-216r. Zu Gloriero - oder Grolier, wie er auch ursprünglich hiess vgl. Färber 1987, S. 198-219.

654 Gemäss Giorgio Vasari stattete Perino del Vaga sowohl die Wände als auch die Decke mit Fresken aus: Vasari, Vite, V, S. 635-636; Alfarano, De basilicae Vaticanae, S. 64. 
der feierlichen Proklamation der Bulle. Der Text der Papstbulle legte die Vorschriften dazu, wie der thesaurus Ecclesiae den Vicariis Sanctae Catholicae Romanae Praepositis Ecclesiae zugänglich war und wie dieselben Stellvertreter der Kirche diesen auch als Spende der göttlichen Gnade verwalten durften, vor. Mit dem rituellen Akt des Niederlegens der Bulle auf den Sakramentsaltar wurde folglich ein sichtbarer Zusammenhang zwischen dem Sündenerlass und der Architektur der Sakramentskapelle aufgezeigt. Die Architektur der Sakramentskapelle in der Petersbasilika und das dort stattfindende Zeremoniell der offiziellen Verkündigung des anno santo verliehen dem Jubeljahr von 1575 seinen römischen Charakter. Die Neuausrichtung des Kurienzeremoniells muss daher im Zusammenhang mit der Proklamationsbulle zum bevorstehenden Jubeljahr und den ersten Eingriffen in die Petersbasilika unter Gregor XIII. betrachtet werden. Den Einträgen im Tagebuch des Zeremonienmeisters Mucanzio zufolge wurde das innere claustrum nämlich zu einer pulchra aula umgestaltet. In der neuen Raumordnung spiegelte sich unmittelbar die Sitzordnung der diesem Proklamationszeremoniell beiwohnenden Kirchenprälaten. ${ }^{655}$ Im Hinblick auf den Sündenerlass wurde die Verkündigung des bevorstehenden Jubeljahres im Kurienzeremoniell bewusst als sakramentale Feier verankert. Die auf eine bestimmte Zeit begrenze Sündenvergebung wurde dadurch selbst zum Sakrament erhoben. Die neue Petersbasilika fungierte dabei als der Ort, an dem die indulgentiae in zeremonieller Hinsicht als Sakrament betont wurden. Demzufolge nahm der Ablass selbst das Zentrum im rituellen Vollzug der sakramentalen Verwaltungspraxis, aus der sich im Rom des anno santo die frömmigkeitsstiftende Dynamik des Pilgerflusses zwischen den vier Hauptkirchen entfaltete, ein.

In dieser Ritualisierung des Ablasses spiegelte sich ein innerhalb der römischen Kurie bestehendes Bedürfnis der Beantwortung der Frage, wie sich der päpstliche Herrschaftsapparat anlässlich liturgischer Feiern als geschlossene Eintracht präsentieren konnte. Die Ausprägung dieser Einheit der Kurie ging nun über die theologischen Gren-

655 BAV, Chig.L.II.30, f. 216r-217r: Preparatus fuit ibi locus adhaerens parieti Ecclesiae repiciens Claustrum inter ipsam Portam maiorem et aliam Portam à sinistro latere ingredientium pulchris auleis ornatus, ubi sedilia pro quibusdam Praelatis apposita, ac duo Pulpiti unus à dextris, et alter à sinistris pariter tapetibus ornati. Praelati ibi sederunt Vicecamerarius, seu Urbis Gubernator, cum aliquot Clericus Camerae ac non nulli scutiferi, et Cubicularij hinc inde steterunt vocati, pro ut etiam non nulli servientes Armorum seu Marzzerij. Sedentibus ergò praedictis Praelatis ascendi Pulpitum praedictum à dextris cotta indutus, litteras Jubilei apertas manibus gerens. Alter verò ex Cantoribus Cappellae aliud Pulpitum ascendit easdem litteras vulgari sermone descriptus deferens, et statim Tube ac Tympana per modicum temporis spatium sonnerunt. Tum facto silentio coepi alta voce legere praedictus litteras in latino unia vocis tono nisi quantum in fine principij in ultima syllaba horum verborum Gregorius XIII episcopus vocem per tres tonos declinavi. Lectis praedictis litteris alter qui à sinistris erat in pulpiti easdem legit italico sermone. Quibus peractis iterum tubae personuerunt, et Tympana, et bombardae quae erant in Platea crepuerunt multa cum letitia. Completo huiusmdi actu Publicationis, in quo Castris S. Ang.li bombarde non fuerunt exoneratae ne per Urbem erederetur tunc Benedictionis solemnis aetum fieri, et propterea amplius ad illam Populus non accederet, accessi ad Cappellam ubi celebratur Missa iuxta solitum 
zen der durch die Dominikaner propagierten Theologie des Abendmahls hinaus. Während des Boncompagni-Pontifikats Gregors XIII. wurde der Portikus der Petersbasilika mit einem Bildprogramm ausgestattet, mit dem bewusst auf diese Beziehung zwischen Kurienzeremoniell und römischem Stadtraum hingewiesen wurde. Diese Ausstattung des Eingangsbereiches von San Pietro nahm die späteren Regelungen des Kurienzeremoniells im Nachfolgepontifikat Sixtus' V., mit denen die Gläubigen ad limina Apostolorum geführt werden sollten, vorweg. Schon anlässlich des anno santo 1575 wurden die apostolischen Grenzen Roms als Schwellen eines Eingangs in das Himmelreich Gottes verstanden. Dieses Verständnis der limina Apostolonum gab das Bildprogramm zur Ausmalung der Wandfelder über den Eingangspforten der Petersbasilika vor, wodurch die ehemaligen pitture antiche ersetzt wurden:

Nell'anno del Signore 1574 Gregorio XIII fece di nuovo una bella soffitta a questo portico con soi arme, lo fece anche tutta inbiancare et buttare giù le pitture antiche che erano sopra le porte, fece fare certe altre bellissime nuove dall'Eccel.o Maestro Lorenzo Federico Zuccaro, cioè sopra la porta Judicij quando S. Andrea menò S. Pietro a Cristo. Et sopra la porta Raviniana quando S. Pietro pescava et Zebedeo con li figli, et sopra l'Argentea quando Xro date le Chiavi a S. Pietro disse pasce ove meas, et sopra la Romana quando Petrus et Johannes introibant in Templum ad horam orationis nonam. Et sopra la porta Guidonea quando in umbra Petri sanabantur infermi. Fece ancora accomodare dette tavole de marmo de S. Gregorio Primo et allora per la grande antiquità è cascata tutte quelle belle reliquie de incostature de bellissimi porfidi et marmi che demonstravano detto portico et tutta la facciata essere stata de quel modo. ${ }^{656}$

Teilweise lässt sich die heute nicht mehr erhaltene Dekoration aus zwei im Département des Arts Graphiques de Musée du Louvre aufbewahrten Zeichnungen Raffaellino da Reggios rekonstruieren. Sie zeigen Raffaellinos Bildgestaltung für die erste Szene der Hinführung des heiligen Petrus zu Christus (Abb. 20a \& 20b). Bei diesem Bildprogramm handelte es sich - wie es der Künstlerbiograph Karel van Mander in seinem Schilder-boeck festhielt - um Historien aus dem Leben des Apostelfürsten Petrus. ${ }^{657}$ In seinem modello konzentrierte sich Raffaellino auf die Beantwortung der Frage, wie der

656 BAV, Arch.Cap.S.Pietro. G.5, f. 13r-v. Zur Stiftung einer kurialen Eintracht vgl. auch Maffei, Annali, I, S. 142-145. Die neue Dekoration des Portikus von San Pietro in Vaticano hielt ebenfalls Musotti in einer an Gregor XIII. adressierten memoria fest: BAV, Bonc.D.5, f. 181v-182v.

657 Van Mander, Schilder-boeck, c. 193r: „Noch voor de Kercke van Pieters, boven de deuren, zijn van hem twee historien, eene daer Petrus en Ioannes den Creupelen voor den Tempel ghenesen. Hier heeft hy moeten volghen d'ordinantie van Raphael d'Vrbijn, die in des Paus tapijten comt: maer hy en heeft dese ordinantie niet verslimt, dan alles seer aerdich op't nat geschildert. Hier sietmen schoon lakenen, en tronien, en alles seer constich en veerdich ghehandelt. D'ander historie is, daer Andreas Petrum zijnen broeder brengt tot Iesum, en daer sy Ioannem de Dooper verlaten, hier sietmen schoon vlacke lakenen, en een aerdich verschiet, met een Ioannes predicatie, met schoon boom-struycke, alles op een heerlijcke en veerdighe wijse van schilderen ghedaen wesende.“ Vgl. auch Vaes 1931, S. 343. Die in Czére 1998, S. 68, und in Marciari 2006, S. 189, reproduzierte Zeichnung aus dem Kunstmuseum in Budapest scheint, wie jüngst m. E. Bolzoni 2016, S. 156 richtig beobachtete, eine Kopie dieser beiden Zeichnungen Raffaellinos aus dem Louvre zu sein. Zur Bi- 
Moment, in dem Christus sitzend die beiden Apostel Petrus und Andreas empfängt, darzustellen sei. Gegenüber diesem ersten Entwurf weist die zweite Zeichnung eine diagonale Aufteilung zwischen Vorder- und Hintergrund auf. Raffaellino da Reggio gelang es damit, die Beschreibung aus dem Johannesevangelium über die Auffindung des Messias (Jh 1, 40-42) als eine Szene darzustellen, in der die Teilnahme der gesamten Kirchengemeinde an einem heilsgeschichtlichen Augenblick mittels der Figur des Apostelfürsten realisiert wurde. Petrus wurde zur Leitfigur nicht nur hinsichtlich der Blickführung der sich zum Zeitpunkt der Eröffnung des Jubeljahres auf der Piazza San Pietro versammelnden Gläubigen, sondern wurde zum Leitbild für die gesamte rituelle Ausführung des Kurienzeremoniells stilisiert. In Raffaellino da Reggios zweiter Entwurfszeichnung nimmt die Kirchengemeinde den gesamten Bildhintergrund ein. Die Figuren reihen sich entlang der Armbewegung Johannes des Täufers auf. Die Anbindung dieser Gemeinde an die Figur des Erlösers wird über den Apostelfürsten Petrus bewerkstelligt. Raffaellino nahm diese Anbindung der gläubigen Kirchengemeinde an Christus in der Szene der Schlüsselübergabe wieder auf (Mt 16,19). Die Szenen auf dem Portikus der Petersbasilika stellen somit die Eintracht zwischen Christus und dem Apostelfürsten Petrus dar und zeichnen Petrus als mediator des göttlichen Heilsgeschehens aus. Er verbindet Kraft seiner Binde- und Trenngewalt die Kirchengemeinde mit dem Reich Gottes. Durch diese potestas des Apostelfürsten wird jedem Gläubigen für eine bestimmte Zeit der Sündenerlass ermöglicht. Das Bildprogramm im Portikus der Petersbasilika lehnte sich demgemäss nicht an Raffaels Tapisserien der Apostelgeschichte an, wie es Karel van Mander noch meinte. Die Szenen wurden gemäss den im Breviarium Romanum enthaltenen Lektionen zum Festtag der beiden Apostelfürsten Roms - Petrus und Paulus - ausgewählt. Francesco Mucanzios Einträge in seinem Zeremonialtagebuch hielten zusätzlich fest, dass der Boncompagni-Papst beschloss, die Oktav dieses Festtags auch auf das Fest der heiligen Katharina von Siena zu übertragen, da dieses in die Oktav der beiden Apostelfürsten fiel. ${ }^{658}$ Die Petersbasilika nahm mit den übrigen drei Patriarchalbasiliken Roms einen zentralen Platz innerhalb der erwähnten Schatztheologie ein. An der Basilika des Apostelfürsten zeigte sich die Erlesenheit des Titelheiligen als vicarius Christi, welcher der sich auf das anno santo vorbereitenden Kirchengemeinde den göttlichen Sündenerlass ermöglichte. Dieselbe Vorstellung der indulgentia wurde entsprechend auch auf die drei übrigen Hauptkir-

ographie Raffaellinos als einer derjenigen Maler in Rom, die hauptsächlich für den Fassadendekor verschiedener Residenzhäuser in der Stadt gepriesen wurden, vgl. Baglione, Vite, I, S. 25-27; ibid. II, S. 244-257; AKL 2018, Bd. 97, S. 376; DBI 2012, Bd. 77, S. 359-363.

658 BAV, Chig.L.II.30, f. 242v. Für das Kurienzeremoniell am Festtag der beiden Apostelfürsten vgl. dann auch weiter ibid., f. 243v-244v. Für die entsprechenden Passagen im Breviarium Romanum vgl. Brev. Rom. (MLCT, 3), S. 797-806. In der vierten Lektion zum officium der ecclesia von San Paolo fuori le mura wurde eine Passage aus Augustinus, De gratia et libero arbitrio, integriert, in welcher die entscheidende Frage gestellt wird, wem die corona iustitiae zurückgegeben werden sollte, wenn der „barmherzige Gottvater“ (misericors pater) die Gnade (gratia) verleiht. 
chen übertragen. Anhand der vier Hauptkirchen Roms konnte die Kurie mit ihrem Zeremoniell der nur über einen begrenzten Zeitraum verfügbaren Gnade ein spezifisches Bild der Ecclesia betonen. Im Zeremoniell zum anno santo begann die Kurie anhand der sichtbaren Wesenszüge römischer pietas ein spezifisches Bild der Romana Ecclesia zu gestalten.

Im Zentrum dieser Ausgestaltung stand die mittelalterliche Schatztheologie. Der in der Papstbulle erwähnte Kirchenschatz (thesauro ecclesiae) wurde gemäss Augustinus als das vergossene und nun angesammelte Blut der Märtyrer verstanden. ${ }^{659}$ Um das Blut der Märtyrer als essentiellen Bestandteil der Ecclesia Romana verstehen zu können, wurde es mit dieser in eine direkte Nachfolge des Kreuzesund Messopfers Christi gebracht. Der Sündenerlass ergoss sich dementsprechend aus diesem in der römischen Kirche angesammelten Blut der Märtyrer. In der Traktatliteratur, in der das anno santo ausgelegt wurde, wird auch der Zusammenhang zwischen einer solchen auf das Blut der Märtyrer konzentrierten Schatztheologie und den vier Patriarchalbasiliken Roms erläutert. In diese Literatur lässt sich auch der bereits vorhin besprochene Traktat des polnischen Kanonikers Treter über die Roma Santa einordnen. Vor allem Treter macht in seiner Abhandlung diesen $\mathrm{Zu}$ sammenhang zwischen der Schatztheologie und den vier in Cavalieris Stich dargestellten Hauptkirchen Roms deutlich:

Giudaico fu figura della libertà, la quale ha Giesu Christo per mezo della sua passione e morte acquistata; acciò se la godiamo nella futura gloria dei beati. E perche nessuno può detta libertà conseguire se non si liberà prima della servitù del peccato, però la Santa Madre Chiesa mutando quelle cerimonie esteriori de Giudei in una spirituale utilità de suoi figliuoli ha ordinato anch'ella l'anno del Santo Giubileo, nel quale ci deliberassimo una volta da dovero di mondarci con vero pentimento di tutti i peccati per per tutta la vita nostra commessi. Et essend per gratia della sede Apostolica (alla quale s'appartiene dispensare li tesori della chiesa) veramente assoluti da peccati per mezo del sacramento della penitenza diventiamo servi di Dio, e produciamo li frutti e l'opere sante, e conseguitiamo poi al fine la vita eterna. [...] dico facciano tutti penitenza, per mezo della quale si scancellino, i peccati e racquistino la santità, e la giustitia già perduta, \& in questa maniera diventino partecipi, della gratia la quale si degna Christo offerirci per il suo Vicario. Ma più facilmente visitato che haverete le quatro chiese qui dipinte,

659 Augustinus, Enarrationes in psalmos, in: PL, Bd. 36, S. 1013: Effuderunt sanguinem eorum sicut acquam, id est, abundanter et viliter: in circuiti Jerusalem. Si Jerusalem terrenam urbem hic accipimus, eorum sanguinem intelligimus effusum in circuitu ejus, quos hostes extra muros reperire potuerunt. Si autem Jerusalem illam intelligimus, de qua dictum est, Multi filii dersertae, magis quam ejus quae habet virum, circuitus ejus est per universam terram: in ea quippe lectione prophetica, ubi scriptum est, Multi filii desertae, magis quam ejus quae habet virum, paulo post ei dicitur, Et qui eruit te, Deus Israel universae terrae vocabitur (Is 54,1-5). Curcuitus ergo hujus Jerusalem in hoc psalmo intelligendus est quosque tunc fuerat eadem Ecclesia dilatata, fructificans et crescens in universo mundo, quando in omni parte ejus persecutio saeviebat, et martyrum stragem, quorum sanguis sicut acqua effundebatur, cum magnis lucris thesaurorum coelestium faciebat. Zur mittelalterlichen Schatztheologie vgl. grundlegend Burkart 2009, S. 55-59. 
conoscerete quanto \& a qual fine s'affatichino i Romani e tutti coloro i quali per questa medesima cagione son venuti in questa Santa Città da diverse parti del mondo. ${ }^{660}$

Die Auslegung des späteren Kanonikers von Santa Maria in Trastevere stimmt mit dem Wandel des Kurienzeremoniells überein, da die vier Patriarchalbasiliken Roms zusammen mit dem Sakrament der Busse verbunden wurden. Im Text der päpstlichen Verkündigungsbulle zum Jubeljahr vom 10. Mai 1574 wurde diese Verbindung zwischen den vier Hauptkirchen der Stadt mit der sakramentalen Kraft der Lossprechung von Sünden ebenfalls betont, indem die Rombesucher dazu aufgerufen wurden, die in den vier Patriarchalbasiliken aufbewahrten Reliquien zu besuchen. ${ }^{661}$ Entsprechend diesem päpstlichen Aufruf musste im Kurienzeremoniell eine Neuinszenierung der Reliquien stattfinden, mit der nicht nur die vier Hauptkirchen, sondern alle sieben Pilgerkirchen Roms als Orte, an denen sich der Sündenerlass gegenüber den Gläubigen sichtbar ausführen liess, inszeniert werden konnten. Auf der Druckgraphik, mittels welcher die zeremoniellen Vorbereitungen zum anno santo rekonstruiert werden können, ist eine Bildsprache zu erkennen, die das Nachleben der Märtyrer in den Reliquien mittels der Heiligtümer der sieben Hauptkirchen ausdrückt. Giovanni Battista de' Cavalieris Roma Sancta zeigt, wie der Pilgerfluss in der Stadt einem Fluss des gespendeten Sündenund Gnadenerlasses gleicht. Stefano Du Péracs Le sette chiese di Roma präsentierte hingegen zum ersten Mal die der sieben Hauptkirchen an den über das Blut der Märtyrer angesammelten Schatz (Abb. 21). Du Péracs Stich wird nämlich von einer Inschrift, in welcher die Vorrangstellung der vier Patriarchalbasiliken betont wird, begleitet:

LE SETTE CHIESE DI ROMA / Per esser venuto l'anno Santo Jubileo con/cesso da Nostro Sig.re Gregorio XIII secondo / lantico consueto e fatto questo disegno, con il / circuito de Roma, dove si vedono dette chiese / cavate dal naturale, et se on sono poste nel / suo luogo, ogni persona iuditiosa conoscera / depender la causa per non haver piu spatio / Di queste sette chiese quattro sono le privile/giate segnati con li Santi à chi sono de/dicate, et con una + et in esse si piglia il / Santo Jubileo, ilquale i Dio ci dia sua Santa / pace per poterlo acquistare nel presente / anno 1575. ANT. LAFRERI ROMAE. ${ }^{662}$

660 Treter, Roma Santa, c. B2v. Vgl. auch weiter Martin, Roma Sancta, S. 8-9; Pientini, Grandezze del Sacro Giubileo, c. A2v-A3r.

661 Schmidt 1949, S. 71: Quo quidem anno durante qui vere poenitentes et confessi beatorum Petri et Pauli apostolorum basilicas et sancti Ioannis Lateranensis ac sanctae Mariae Maioris in Urbe ecclesias triginta continuis vel intermissis diebus semel saltem in die, si Romani vel Urbis incolae fuerint, si vero peregrini quindecim diebus devote eodem modo visitaverint, ac pro ipsorum totiusque christiani populis salute pias ad Deum preces fuderint, plenissimam omnium peccatorum suorum indulgentiam et remissionem [...]. Vgl. dann auch jüngst Wisch 2012, S. 275-277.

662 Vgl. die jüngsten Untersuchungen zum Stich bei San Juan 2011, S. 112-116; Woodward 2007, S. 10-11; Witcombe 2008, S. 253; Bury 2001, S. 121-135; Prosperi Valentini Rodinò 1998, S. 285-287; Wisch 2012. Im Übrigen stellte Du Péaracs Darstellung auch hinsichtlich des in die Druckgraphik mittlerweile eingeflossenen Bedürfnisses nach einer kartographischen Auseinandersetzung mit der städtischen Topographie Roms eine Neuerung dar. Vgl. hierzu v. a. Miller 2003, S. 103-110; Frutaz 1962; Cantile 2015, S. 25-38; Ferrante 2015, S. 39-40; Maier 2015, S. 133-142. 
Der Augustinermönch Onofrio Panvinio hatte sich in seinem posthum erschienenem Traktat De praecipuis urbis Romae sancioribusque basilicis von 1570 ebenfalls dieser Vorstellung gewidmet. Deshalb eignete sich Panvinios Abhandlung als Grundlage für die weiteren, während des Jubeljahres 1575 entstandenen Pilgerführer zu den sieben Hauptkirchen Roms. Sowohl der Stich Du Péracs als auch Panvinios Traktat nahm die nach dem Tridentinum neu erstarkte Reliquienverehrung innerhalb des römischen Stadtraumes auf. Die in Du Péracs Stich vor den vier Hauptkirchen stehenden überlebensgrossen Figuren der Apostel verweisen darauf, wie in den aufbewahrten Reliquien, den viva membra Christi et templum Spiritus sancti, die Erfüllung des göttlichen Heilsversprechens weitergeführt wird. ${ }^{663}$ Mit der Verehrung dieser monumentalen Reliquienkörper vor den einzelnen Hauptkirchen wird schliesslich ein ekklesiologisches Verständnis sowohl des materiellen als auch des spirituellen Kirchenschatzes hervorgehoben. Dieser Kirchenschatz selbst repräsentierte sodann die Ecclesia.

Das Jubeljahr 1575 wurde zum Anlass einer frömmigkeitsstiftenden Andacht aufgeführt, um die von den Protestanten geäusserte Kritik an der Reliquien- und Heiligenverehrung wieder mit Hilfe des Kurienzeremoniells angemessen zu begründen. ${ }^{664}$ In der rituellen Verwaltung der sakramentalen Lossprechung der Sünden liess sich im Jubeljahr Gregors XIII. der thesaurus ecclesiae, der über die Märtyrerund Apostelreliquien sichtbar überliefert war, als Zusicherung für die Spende der indulgentiae zeremoniell gestalten. Die Kurie hatte sich dabei auf eine von der Hochscholastik übernommene Schatztheologie gestützt. Dieser theologische Umgang damit, wie der durch das Blut der Märtyrer akkumulierte Kirchenschatz auszulegen war, zeigte sich allen voran in der Heiligenverehrung selbst. Dies erlaubte es der Kurie in den römischen Stadtraum eine spezifische Zeremonialkultur wieder einzuführen, die gleichzeitig die nötigen Grundlagen der göttlichen Sündenvergabe anbot. Diese bewusste Übertragung des Kurienzeremoniells auf die urbane Topografie begann sich bereits 1573 innerhalb des Dominikanerkonvents von Santa Maria sopra Minerva anzubahnen, wo die Compagnia del Rosario mit der sienesischen Bruderschaft in einen wegweisenden Konflikt geriet, der das Überleben des Kurienzeremoniells im Stadtraum entscheidend bestimmen sollte.

663 COD, S. 775; Panvinio, Le sette chiese, S. 1-2. Panvinio hatte bereits 1560 alle Kirchen Roms gründlich zusammengestellt (BAV, Vat. lat. 6780), woraus er dann seinen Traktat über die sieben Hauptkirchen Roms ableitete. Gemäss Waetzoldt 1964, S. 10, und Perini 1899, S. 170-180, beabsichtigte Panvinio ein zehn Bände umfassendes Werk mit dem Titel De antiquis et recentioribus ecclesiis, monasteriis, coemeteriis herauszugeben.

664 Martin, Roma Sancta, S. 56: „Et dubitamus adhuc Romam tibi Christe dicatam in leges transisse tuas? [...] Thus these fathers write of Rome in their time. And we se at this day that it keepeth on the same course stil: and the whole effect is of all these sayinges and doinges, that the honour of Christ and his Saintes hath confounded the devil and his Idols, and therfore wonderfull maice or exceding blindenesse it is in our haeretikes that make this Citie the chiefe See of Idolatrie, and this people the greatest Idolatours, for doing these thinges which have been the confusion of Idolatrie." 


\subsection{Ein Kontrapunkt im städtischen Kurienzeremoniell}

Bislang hat sich die Forschung kaum mit der Frage auseinandergesetzt, wie im Kurienzeremoniell die Reliquien- und Heiligenverehrung in Bezug auf die sakramentale Verwaltungspraxis gefasst wurde. Diese Frage kam innerhalb der Kurie in dem Moment auf, als der päpstliche Herrschaftsapparat seine Hegemonie über die Heilserlangung zeremoniell auf die heiligen Reliquien auszudehnen begann. Diese Ausdehnung des kurialen Monopolanspruchs auf den göttlichen Gnadenerlass lässt sich am deutlichsten anhand der Katharinen-Kapelle in Santa Maria sopra Minerva, die in einen der Rosenkranzmadonna gestifteten Kapellenraum umgewandelt wurde, nachzeichnen. ${ }^{665}$ Die Umwidmung rief einen Konflikt zwischen den beiden in der Minerva ansässigen Bruderschaften des Rosario und der Sienesen hervor. Aus Sicht der Sienesischen Bruderschaft sollte dieser Konflikt sogar bis zum Pontifikat Alexanders VII. Chigi ungelöst bleiben. ${ }^{666} 1573$ erlaubte Angelo Capranica der Rosenkranzbruderschaft ihre Sitzungen in derjenigen Kapelle von Santa Maria sopra Minerva halten zu dürfen, die der heiligen Katharina gewidmet war. Die Rosenkranzbruderschaft beabsichtigte aber diese Kapelle für ihre Sitzungen architektonisch neu auszugestalten und das Gewölbe mit Szenen, die dem Rosenkranzgebet entlehnt sind, zu schmücken. Die Dekoration des Gewölbes der Cappella Capranica mit den Mysterien des Rosenkranzes nahm Marcello Venusti zwischen 1573 und 1579 in Angriff (Abb. 22). Mit seinem Dekorationsschema trug Venusti dazu bei, dass dieser Konflikt zu Gunsten der Rosenkranzbruderschaft ausging. Die Kurie hatte sich ebenfalls an Ausgang dieses Konfliktes mit einem spezifisch für diesen Kapellenraum gestalteten Zeremoniell beteiligt, indem während des Jubeljahres 1575 der Rosenkranzbruderschaft mehrfach gewährt wurde, Ablässe vergeben zu dürfen. ${ }^{667}$

665 Fünf Jahre nach dem Tod des Heiligen aus Siena wurde der heiligen Katharina ein Grabmal aus Marmor in der rechts neben der cappella maggiore gelegenen Kapelle - der späteren Cappella dell'Annunziata - durch Fra Raimondo da Capua gestiftet. Ab 1446 unterstand sie dem Patronat des Kardinals Domenico Capranica. Vgl. Bianchi 1988, S. 15-62; DBI 1976, Bd. 19, S. 147-153; Pagano 2012, S. 1246-1249; Barclay Lloyd 2012, S. 113.

666 Der Konflikt ist in einem von Carlo Capranica 1660 an Alexander VII. verfassten memoriale in BAV, Chig.III.81, f. 1r-v, überliefert. Eine weitere Abschrift dieses Schreibens findet sich bei Boccardi 2006, S. 53-57. Es ist an dieser Stelle entscheidend, anzumerken, dass dieser Konflikt in dominikanischen Schriften völlig ignoriert wurde. Zwei consilia pro Natione Senensi sowie ein offenbar hundertfach gedrucktes Briefschreiben der in Siena selbst ansässigen Confraternita di S. Caterina sind ebenfalls überliefert. Beide consilia der giureconsulti Bernardino Borghesi und Mario Marzi befinden sich in ASV, Fondo Borghese IV, 234B, f. 87r-89r sowie ivi, f. 91r-93v. Das Schreiben der Confraternita in Siena findet sich abgedruckt in Catastini 1890, S. 59-60; Pagano 2012, S. 1256-1257. 667 Ein Summarium indulgentiarium der Bruderschaft des Rosenkranzes von Santa Maria sopra Minerva befindet sich in ASV, Misc. Arm. II, 146, f. 118r-121v. Vgl. zudem auch die beiden handschriftlich überlieferten Beschreibungen der Compagnia in BAV, Vat. lat. 11883, f. 27v; BAV, Vat. lat. 11889, f. 41r-44v. Letzteres scheint womöglich eine aus ASV, Misc. Arm. VI, 15, f. 21r-24v stammende Abschrift zu sein. Zur römischen Compagnia del Rosario vgl. Martin, Roma Sancta, S. 214-218. 
Anlässlich des Heiligen Jahrs 2000 wurde die Cappella Capranica und ihr Freskenschmuck vollständig restauriert. Die Restaurationen trugen wesentlich dazu bei, eine Händescheidung zwischen den bis 1579 ausgeführten Malereien Marcello Venustis und den darauffolgenden Arbeiten Giovanni de' Vecchis ausfindig zu machen. ${ }^{668}$ Das Bildprogramm der Fresken Venustis fügt sich in eine reiche Stuckdekoration ein. Die Stuckarbeiten, die zum selben Zeitpunkt wie Venustis Fresken fertiggestellt wurden, nutzte der Maler als geeigneten Rahmen für die Ausführung seiner Fresken. Das Bildprogramm umfasst fünfzehn Szenen der Misteri del Rosario. Das Dekorationsschema verbindet die Misteri gloriosi der Wiederauferstehung, der Himmelfahrt, der Ankunft des Heiligen Geistes und der Himmelfahrt Mariens sowohl mit den Misteri dolorosi der Passionsgeschichte Christi als auch mit den Misteri gaudiosi der Geburt Christi. ${ }^{669}$ Als die Cappella Capranica zwischen 1573 und 1579 umgestaltet wurde, wurde das Grabmal der heiligen Katherina von Siena in die Sakristei verlegt. Die Mitbrüder der Confraternita dei Senesi beklagten sich bei der Rosenkranzbruderschaft über diese Verlegung des Grabmals ihrer Heiligen. ${ }^{670}$

Man sah vor, dass das Bildprogramm bis zum Jubeljahr 1575 fertiggestellt werden sollte, um die Fresken am Tag der jährlich stattfindenden Prozession der Rosenkranzbruderschaft enthüllen zu können. Ein im Archiv der Minerva aufbewahrtes Dokument hält fest, dass man mit den Arbeiten nach dem 26. Mai 1573 begann. ${ }^{671}$ Das fertiggestellte Bildprogramm im Deckengewölbe nimmt allerdings in den dargestellten misteri nie wirklich Bezug zur Rosenkranzmadonna. Deshalb beauftragte die Compagnia den Maler Marcello Venusti mit der Anfertigung eines Altarbildes, das aber nie fertiggestellt wurde, da Venusti im selben Jahr, als er die Fresken für die Kapelle fertigstellte, starb. Das später in der Cappella Capranica angebrachte Altarbild stammte ursprünglich aus der Cappella di San Giacinto. ${ }^{672}$ Das Gewölbe zeigt somit nur die aus dem Neuen Testament abgeleiteten Geheimnisse des Rosenkranzes. Das Dekorationsschema Venustis könnte somit als eine bewusste Verschränkung zweier Strömungen der Heilsgeschichte verstanden werden, wodurch die mariologische Auslegung des Rosenkranzgeheimnisses in das mysterium der Auferstehung und Himmelfahrt Christi überläuft. Die Compa-

668 Strinati 2001, S. 65-70. Zur Dekoration vgl. Capelli 2002, S. 73-80; Tosini 2010, S. 517-522; Heideman 1993, S. 149-162; idem 1989, S. 451-464; Wegner 1994, S. 755-775; Strinati 1984, S. 395-428.

$669 \mathrm{Zu}$ den Fresken Venustis vgl. Baglione, Vite, I, S. 20; Celio, Memoria, S. 24; Titti, Nuovo studio di pittura, S. 159; Pio, Vite, S. 199-201; Masetti, Memorie, S. 35; Black 1989, S. 245-246; Hall 1999, S. 211-212; Zeri 1997, S. 87. Für die drei Gruppen des Rosenkranzmysteriums vgl. Martin, Roma Sancta, S. 216-217.

670 BAV, Chig.III.81, f. 7r-8v. Zur Situierung des Heiligengrabmals vgl. Bianchi 1988, S. 48-49.

671 Strinati 1984, S. 408-409.

672 Capelli 2002, S. 78. In dem einen Tag vor seinem Tod angefertigten Testament, erklärte sich Venusti sanus Dei gratia mente et intellectu sed corpore infirmus, zit. n. Bertolotti 1985, Bd. 1, S. 104. Offensichtlich hinderte ihn dieser Zustand auch daran, das Bildprogramm in der Cappella Maccarani noch fertigzustellen, welche das Noli me tangere präsentieren sollte. Vgl. hierzu dann Capelli 2001, S. 31; Kat. Arcevia 2002, S. 86-88. 


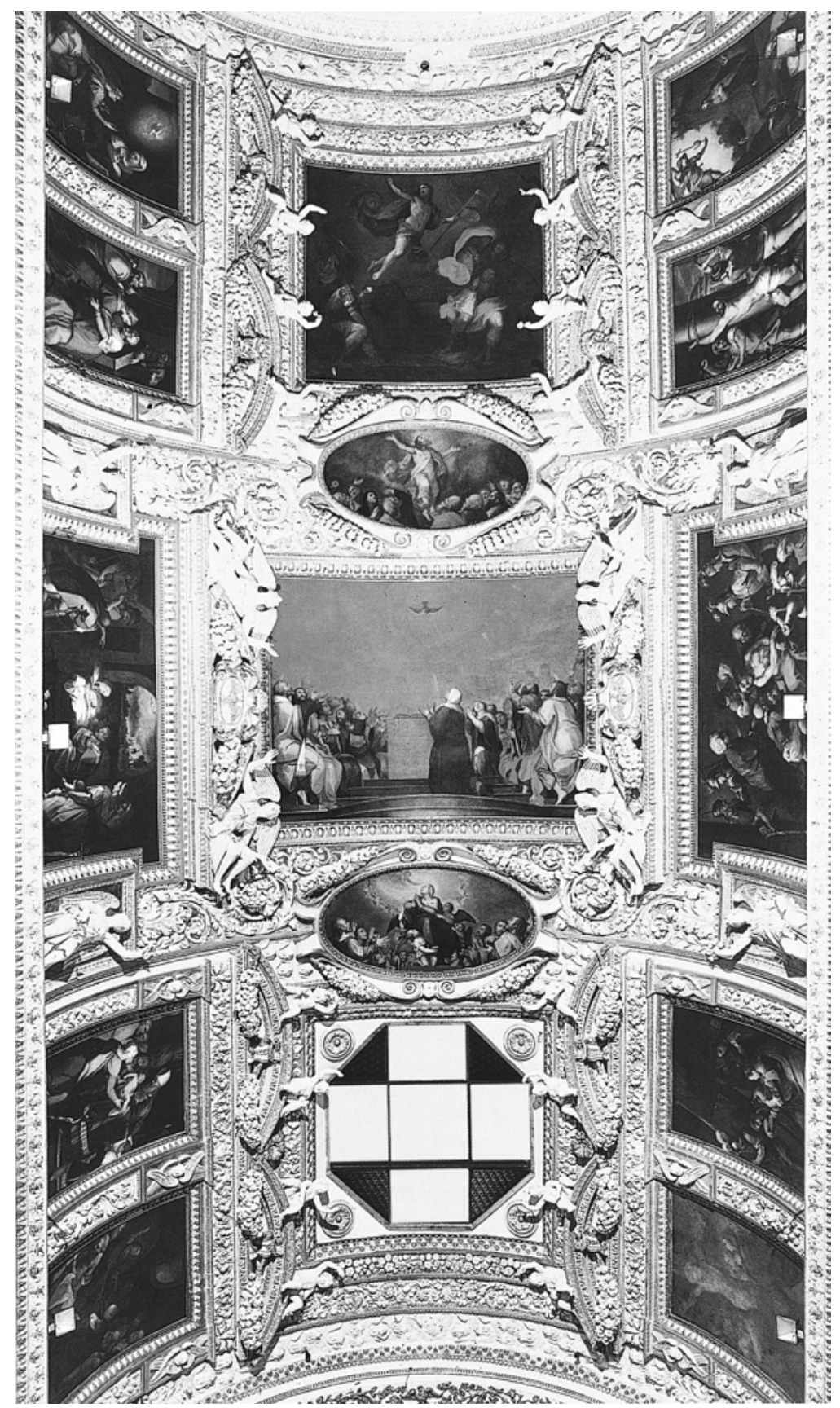

Abb. 22: Marcello Venusti, Die Mysterien des Rosenzkranzes, Deckengewölbe, 1574-1576, Cappella Capranica, Santa Maria sopra Minerva, Rom. 
gnia del Rosario konnte mit dem Bilderschmuck der Cappella Capranica die Mysterien des Rosenkranzes an eine theologische Christozentrik, welche die Bruderschaft der Sienesen in der Verehrung ihrer Heiligen schlichtweg noch nicht vorweisen konnte, anlehnen. Das Anrecht, die Kapelle entsprechend für ihre Zusammenkünfte der Rosenkranzbruderschaft neu gestalten zu dürfen, und die vom BoncompagniPapst an dieselbe Bruderschaft zugesprochenen indulgentiae können daher als Bestätigung der Eingriffe seitens der Compagnia del Rosario in diesen Kapellenraum betrachtet werden. ${ }^{673}$ Zudem spricht die Bildprogrammatik für eine Auftraggeberschaft Angelo Capranicas, denn Capranica war einer der guardiani der Gonfalone-Bruderschaft. Zusätzlich war er dem Oratorio del Crocifisso eng verbunden. Capranica musste somit die Bildprogramme in den beiden Oratorien gekannt haben, die ebenfalls eine Christozentrik vermittelten. Marcello Venustis Fresken brachten die Ästhetik der Rosenkranz-Bruderschaft in eine große Nähe zu den Ausschmückungen in den Oratorien des Gonfalone und dem Santissimo Crocifisso. Zum Zeitpunkt ihrer Ausmalung repräsentierte die Cappella Caranica eine Bauhütte, in welcher bildprogrammatisch das christologische Heilsmysterium ausgelegt wurde. Solange die Bruderschaft den Übergang von einem mariologischen Heilsgeschehen in das Mysterium des christlichen Heilsversprechens demonstrieren konnte, behielt das Rosenkranzgeheimnis seine liturgisch hohe Rangstellung gegenüber anderen Frömmigkeitsgebeten.

Ab dem Zeitpunkt, als die Compagnia del Rosario die Erlaubnis bekam, die Cappella Capranica für ihre Zusammenkünfte nutzen zu dürfen, wurde der Dominikanerkonvent von Santa Maria sopra Minerva stärker in das Kurienzeremoniell zum Festtag der Verkündigung Mariens eingebunden. Der Eintrag im Tagebuch des Zeremonienmeisters Francesco Mucanzio für die am 25. März 1573 stattgefundene Feier hält nämlich eine solche rituelle Überführung mariologischer Heilsgeschichte in das christozentrische Heilsversprechen fest. Der Festtag der Verkündigung Mariens fand am Folgetag der dritten feria nach Ostern statt. Als der Papst und die Kurie vor der Kirchentür von Santa Maria sopra Minerva ankamen, küsste Gregor XIII. das dort aufgestellte Kruzifix und „benetzte“ (aspersi) es mit Wasser. Als der päpstliche Zug danach im Kirchenraum den Chorbereich erreichte, begannen zwei Kardinäle vor dem Heiligen Sakrament der Eucharistie zu predigen. Einer der Prediger, der dem Dominikanerorden selbst angehörte, war der 1570 zum Kardinal gewählte Vincenzo Giustiniani. ${ }^{674}$ Auf die Predigten der beiden Kardinäle folgte eine Messe. Ur-

673 Für die drei wichtigsten Bullen Gregors XIII., in denen er der Rosenkranzbruderschaft von Santa Maria sopra Minerva Indulgenzen zusprach, vgl. Bull. Ord. Praed., V, S. 318, 335-343, 345-346.

674 BAV, Chig.L.II.30, f. 111v-112r: Die 25 eiusdem in festo Annuntiationis B. M. V. Pontifex stola redimitus unà cum Collegio S. R. C. Cardinalium cappis rubeis indutorum equitavit ad ecclesiam B. M. suprà Minervam solito ordine, et pompa. In Porta dictae ecclesiae osculatus fuit Crucem, aspersit se, et thurificatus fuit triplici duetu à Presbitero Cardinali oravit antè Sanctissimum Sacramentum, 
sprünglich hätte diese vor dem Hauptaltar zu Ehren der Jungfrau Maria zelebriert werden sollen. Da aber der Festtag der Verkündigung unmittelbar auf das Osterfest folgte, wurde diese Messe als commemoratio der Osteroktav gefeiert. Damit wurde das österliche officium liturgisch über die gesamte Oktav ausgedehnt. Das Kurienzeremoniell orientierte sich dabei an den Vorgaben des Breviarium Romanum, wonach es de facto ebenfalls zu einer Ausdehnung derjenigen officia, die dem Andenken an das Kreuzes- und Messopfer Christi gewidmet waren, kam. ${ }^{675}$

In seinen Einträgen zu diesem Festtag erwähnt der Zeremonienmeister Mucanzio, dass der Kardinal Alessandrino, Michele Bonelli, die Messe zum Festtag der Verkündigung in seiner Titelkirche von Santa Maria sopra Minerva zelebriert habe. Der Fortschritt der Malereien Marcello Venustis innerhalb der Cappella Capranica waren daher von diesen Messzelebrationen Bonellis abhängig. Bonelli war nämlich auch innerhalb derjenigen Kardinalskommission tätig, die der Boncompagni-Papst zur Lösung des Streites zwischen den beiden Bruderschaften in Santa Maria sopra Minerva - der Titelkirche Bonellis also - einberufen hatte. ${ }^{676}$ Der Eintrag Mucanzios in seinem Tagebuch ist hauptsächlich dem Verhältnis zwischen Messzelebration und der Ausrichtung des Altars gewidmet. Mucanzio beurteilte Kardinal Alessandrinos Messefeier in Hinblick auf die im neuen Missale Romanum enthaltene Aufforderung, die Kirchenaltäre ad orientem auszurichten. Das Kurienzeremoniell für den Festtag der Verkündigung

accepit Paramenta, et inter fuit Missae quam celebravit Rev. D. Card. Justinianus ordinis Praedicatorum. Giustiniani war unter anderem auch als Mitglied der vorhin bereits besprochenen und unter Pius V. einberufenen Kardinalskommission tätig, welche die Confessio Augustana widerlegen sollte. Nach der Kardinalsernennung 1570 kam derselbe Giustiniani dann in die Indexkongregation, um sich spezifisch der Widerlegung der Magdeburger Zenturien zu widmen. Vgl. zu Giustiniani insbes. DBI 2001, Bd. 57; Eubel, Hierarchia catholica, III, S. 44; DHGE, Bd. 21, sub voce. Vgl. auch den nicht gänzlich auf Giustiniani zurückzuführenden Traktat Considerationes habendae in negocio conventualium in BAV, Ott. lat. 1853, I, f. 209r-210r. Vgl. auch seine zwei Briefschreiben an Carlo Borromeo aus dem Jahr 1571 zum Dominikanerorden in Mailand in BAM, F 97inf., f. 423r-v, 440v, 376r-v. 675 BAV, Chig.L.II.30, f. 112r-113r; Brev. Rom. (MLCT, 3), S. 756-759.

676 Vgl. hierzu das Dokument in ASV, Fondo Borghese IV, 234B, f. 87r, in welchem der Streitpunkt auf die Translozierung des Grabes der Sieneser Heiligen folgendermassen pointiert wird: Primum, quia in dicta Cappella erat statua seu imago dictae Sanctae et nulla alia; a qua imagine argumentum sumsit Salvator noster, cum interrogaretur an liceret dare censum Caesari: nam allato numismate ait: Cuius est haec imago? Et cum respondissent Caesaris, dixit: Reddite quae sunt Caesaris Caesari, et quae sund Dei Deo (Mt 22, 17-21; Mk 12, 14-17; Lk 20, 22-25). Si itaque Christus noluit sibi tribuere quae Caesaris erant, ita nec gloriosa semper Virgo Maria, sequendo vestigia iustissimi filii, non intendit occupare quae sunt Divae Catherinae, cum gloriosa sit Dominus in Sanctis suis. (Ps 67,36) Quare merito natio Senen. clamat dicendo: Reddite quae sunt D. Catherinae, Divae Catherinae; et quae sunt D. Mariae, Divae Mariae. Vgl. hierzu Pagano 2012, S. 1250-1251. Zur Erwähnung Kardinals Alessandrino als Messzelebrant in Santa Maria sopra Minerva vgl. die Stelle in BAV, Chig.L.II.30, f. 203v: Missa celebravit in Paramentis albis Cad.lis Alexandrinus nepos sororius feci rec. Pij Papae V. et ipsius Ecclesiae Titularius. Omnia peracta sunt secundum bonas et consuetas caeremonias. 
Mariens sollte die Ecclesia „lebhaft“ (angens) verkörpern. ${ }^{677}$ In seiner Beurteilung der Messefeiern ging es dem Zeremonienmeister Mucanzio darum, wie sich im rituellen Vollzug der Messe die vorgegebene Gebetsrichtung auch in zeremonieller Hinsicht einhalten liess, um dadurch die zur Messe versammelte Kirchengemeinde innerhalb des sakramentalen Heilsmysteriums angemessen hervorheben zu können. Auf der Grundlage der revidierten liturgischen Bücher wurde im Kurienzeremoniell ein Verständnis darüber formuliert, wie im Gebet selbst das Sakrament der Eucharistie dem Kreuzesund Messopfer Christi anzunähern war. Das Kurienzeremoniell sollte schliesslich eine einheitsstiftende Übereinstimmung zwischen Eucharistie und dem Kreuzes- sowie Messopfer sichtbar evozieren. Dieselbe Neigung, das Sakrament der Eucharistie als sichtbare Verkörperung des Messopfers visuell vorzuführen, wird auch im Bildprogramm der Cappella Capranica bemerkbar: Die Bildgruppe der Misteri gloriosi, in denen die Verkündigung Mariens enthalten ist, nähert sich den Misteri dolorosi der Passionsgeschichte an. Diese Annäherung erlaubt es, in den beiden Misteri gaudiosi der Ankunft des Heiligen Geistes und der Geburt Christi - den sakramentalen Charakter hervorzuheben.

Hierfür bediente sich Marcello Venusti einer Bildsprache, die in ihrem Kern noch der Figurendisposition und der Linienführung einer lombardischen Farbartikulation folgte. Mittels des bewussten Einsatzes eines Wechselspiels von chiaroscuri hatte Venusti im zweiten Bildfeld der Gewölbedecke die Szene der Geisselung Christi neu zur Schau gestellt. Venusti verzichtete bewusst auf eine szenisch-architektonische Aufführung der Geisselung in ihrem theatralischen Moment, wie sie noch Federico Zuccari mit seinem Fresko im Oratorium der Gonfalone-Bruderschaft fasste. Stattdessen hebt Venusti in seiner Bildversion der Geisselung Christi stärker die diagonale Richtung hervor, in welche sich das szenische Bildnarrativ entfaltet. Der Maler scheint sich ganz auf die Schwere des gegeisselten Körpers Christi zu konzentrieren, auf den er das Ungleichgewicht zwischen hellem impasto und dunklen Schattenfeldern aufträgt. Diesen contraposto, der sich in der Farbgebung zeigt, nutzte Venusti auch dafür, das Verhältnis der beiden Vollstrecker gegenüber Christus bildsprachlich stärker zu erläutern. In ihrer Anordnung und Bewegung grenzen die beiden Figuren ein weiteres Bildfeld ein, in welchem sich die Geisselung schliesslich ereignet. Dasselbe Feld scheint zudem den ausserhalb des Bildes stehenden Beobachter mit der im Bildhintergrund gezeigten Architektur zu verbinden. Im Gegensatz

677 BAV, Chig.L.II.30, f. 200v-201r: Sed opere praetium erit aliqua circa situationem Altaris describere quae annis praeterritis diversi mode observata fuerunt [...] Retroactis annis ante Pontificatum Pij V. consuetum erat faciem Altaris versus Chorum ponere quamvis eo modo contra Regulam Celebrans super eo respiceret Occidentem, id tamen fiebat ob commoditatem Pontificis, eo Patrum, ipsiusque celebrandis, et ministros quippè alias in congruum, et sine decoro videbatur, dum sic Missa, et caeremoniae peragerentus ob loci angentiam. Verum praedictus Pius V. suo tempore voluit eo modo Altare remanere pro ut ordinarie est, ut celebrans super eo facium verteret ad Orientem, quamquam incommode celebrantis fieret. 
zum Bildprogramm im Oratorio del Gonfalone beabsichtigte Marcello Venusti in der Cappella Capranica nicht die Mysterien des Rosenkranzes als ein sich vor dem Beobachter abspielendes Theaterstück vorzuführen. Der Beobachter wird in der Cappella Capranica selbst dazu eingeladen, an der Passionsgeschichte teilzunehmen. Während sich somit in der Messe das Mysterium des Kreuzes- und Messopfers Christi als sakramentaler Wesenswandel von Blut und Körper den Gläubigen offenbaren sollte, mussten die drei Mysteriengruppen im Rosenkranzgebet das Nachleben der Passionsgeschichte in den Sakramenten selbst enthüllen.

Die Ausgestaltung der Cappella Capranica ist daher im Zusammenhang mit dem rituellen Kreislauf, den die heilsame Dynamik der Eucharistie durchläuft, zu betrachten, da diese Kraft in der Ausgestaltung des Kurienzeremoniells für den Festtag der Verkündigung Mariens im Zentrum stand. Das Kurienzeremoniell legt nämlich dar, wie mariologische Elemente der Heilsgeschichte im christozentrischen Heilsversprechen verwurzelt waren. Die liturgische Eingliederung mariologischer Dimensionen des Rosenkranzes in die Christozentrik des Kreuzes- und Messopfers lässt vermuten, dass die Arbeiten Venustis in der Cappella Capranica ihren bildschöpferischen Höhepunkt zwischen 1574 und 1576 erreicht haben mussten. Im Zeremoniell zum Festtag der Verkündigung wurde die sakramentale Bedeutung des Kreuzes- und Messopfers Christi dafür genutzt, auch die weiteren Festtage, welche die Osterfeierlichkeiten einrahmten, neu auf die Verehrung des Sakraments der Eucharistie auszurichten. Die Sakramente wurden somit im Kurienzeremoniell gezielt innerhalb des rituellen Vollzugs der Messe eingesetzt, um dadurch das Mysterium des Kreuzes- und Messopfers Christi zu betonen. Die päpstliche Gewährung von Ablässen an römische Bruderschaften trug entschieden dazu bei, die indulgentiae selbst als Sakramente betrachten zu können. Denn diese Ablässe durfte die Bruderschaft erst dann an die Gläubigen vergeben, wenn diese eine bestimmte Anzahl an frommen Taten erfüllt hatten. Diese Neubestimmung, wie Ablässe durch römische Bruderschaften zu verwalten waren, machte sich bereits in einer am 6. August 1573 erlassenen Papstbulle bemerkbar. Darin bewilligte Gregor XIII. der Confraternita del SS. Sacramento von Santa Maria sopra Minerva, Ablässe anlässlich ihrer Besuche anderer Kirchen und Altäre spenden zu dürfen. ${ }^{678}$ Sowohl die Rosenkranzbruderschaft als auch die ebenfalls in Santa Maria sopra Minerva sesshafte Compagnia

678 Bull. dipl. rom., VIII, S. 50-52, 51: Praeterea eisdem confratribus utriusque sexus, extra Urbem existentibus, qui in diebus, in quibus stationes in ecclesiis in Urbe et extra illam existentibus habentur, altare seu locum, in quo Sacramentum custoditur, visitaverint, et septies Orationem Dominicam et Salutationem Angelicam recitantes, pro exaltatione fidei catholicae et extirpatione haeresum et infidelium oraverint, easdem indulgentias, quas consequerentur si ea die illam ecclesiam in Urbe et extra eam visitarent, in qua ipsa statio habetur; insuper eisdem confratribus huiusmodi altare seu locum visitantibus, et ut supra orantibus, sexta quaque feria, centum dies; singula vero die in Coena Domini eisdem confratribus vere poenitentibus et confessis septem annos et totidem quadragenas. 
dell' Annunciazione begann ab diesem Zeitpunkt mit Hilfe kurienzeremonieller Feiern ähnliche Strukturen wie die Sakramentsbruderschaft anzunehmen.

Die Verwaltung der Sakramente wurde im Kurienzeremoniell auf die zentrale Bedeutung der Eucharistie ausgerichtet. Im Hinblick auf das anno santo begann die Kurie auch den materiellen Kirchenschatz an dieses Sakrament anzunähern. Die indulgentiae, die den Gläubigen bei der Reliquienverehrung gespendet wurden, stellten eine besondere Art dar, wie göttliche Gnade angehäuft werden konnte. Mittels der Reliquien- und Heiligenverehrung sammelte sich somit eine neue Gattung von Ablässen an. Diesen indulgentiae, die allen voran in der Verwaltung römischer Bruderschaften standen, wurde dann im Kurienzeremoniell ein sakramentaler Bedeutungsstatus zugewiesen, wodurch sie dem göttlichen Gnadenerlass angeglichen wurden. Das Kurienzeremoniell bot somit eine günstige Möglichkeit, Bestimmungen darüber zu formulieren, wie die päpstliche Verwaltung der Ablässe und deren Spende rituell zu vollziehen waren. Damit liess sich ein neues Verständnis der Romana Ecclesia auf der Grundlage sowohl einer von den Aposteln überlieferten communio sanctorum als auch einer congregatio societasque sanctorum begründen.

Die Gestaltung des Kurienzeremoniells anlässlich des Jubeljahres 1575 führte somit ein neues Verständnis darüber ein, wie die Kurie die Sakramente mit Hilfe römischer Bruderschaften für ihre eigenen Zwecke verwalten konnte. Diese Verwaltungspraxis, mittels welcher auch weitere Bruderschaften zunehmend an Sakramentsbruderschaften angepasst wurden, offenbarte eine Kontinuität zwischen apostolischer Vergangenheit und dem sichtbaren Kirchenvermächtnis, das in den Märtyrer- und Heiligenreliquien überliefert war. Cesare Baronios Annales Ecclesiastici stellen daher den ersten erfolgreichen Versuch dar, eine Kirchengeschichte von der sakramentalen Verwaltungspraxis, die vorwiegend durch das Kurienzeremoniell bestimmt wurde, abzuleiten. Indem das Kurienzeremoniell selbst ein Regelwerk der sakramentalen Verwaltungspraxis darstellte, wurde mit der sichtbar-liturgischen Enthüllung heiliger Reliquien und ihrer Verehrung ein neues Kirchenbild geschaffen, auf welches sich Baronio für seine Annales auch in kontroverstheologischer Hinsicht stützen konnte.

\subsection{Per quos evangelium Romae resplenduit}

[...] speciali \& propria nostrae Urbis exultatione veneranda est, ut ubi praecipuorum apostolorum glorificatus est exitus, ibi in die martyrij eorum sit laetitiae principatus. ${ }^{679}$

Während seines Romaufenthalts stellte der englische Pilger Gregory Martin fest, dass neben dem päpstlichen Plenarablass die Vorführung heiliger Reliquien für die zahlreichen Rombesucher eine weitere „spirituelle Belohnung“ während der Osterwoche darstellte:

679 Brev. Rom. (MLCT, 3), S. 798. 
[...] the bishop of Jerusalem did bring it forth at the feast of Easter only to be adored of the people, and not at other times, but for pilgrimes which came very farre of purpose to see it: even so in Rome at this day, there be certen dayes in the yeare when the principal Relikes are shewed in certen Churches, where there is greatest concurse of people, namely at Easter. In so much that in the holy yeare of Jubilee, bycause of newe pilgrimes coming in great troupes everie day, they were shewed for their sakes verie often, as one spiritual reward among the rest of their long pilgrimage [...]. In every Church where these Relikes are reserved and shewed, there is for this purpose in the place of greatest sight and fardest prospect, over an aultar, a square loft walled in upon foure pillers, al of fayre wrought stone, in the middes whereof is a goodly tabernacle so sette that a man may walke round about. Here are the Relikes partly reserved, partly brought thither for that Day. And from this place they are shewed thus. Light round about, A bishope commonly, (sometime an inferiour Prelate,) in his mitre and Cope, with two assistantes, on eche side one, in surplices, the one for Latin, the other for Italian [...]. And that they do thrise, bycause the bishop sheweth every one thrise, turning thrise to the people on three sides, according as they stand round about, and can not see al at once. ${ }^{60}$

Diese Vorführung der Heiligen- und Märtyrerreliquien, die Martin eingehend beschreibt, wurde in ein eigens dafür gedachtes Zeremoniell innerhalb der Messzelebration integriert. In deren Enthüllung wurde der eucharistisch-sakramentale Charakter betont. Die anlässlich des anno santo gedruckten Pilgerführer, wie die Cose maravigliose della città di Roma und Angelo Pientinis Pie Narrationi, wiesen den Reliquien innerhalb des städtischen Parcours einen besonderen Stellenwert zu. Die Glanzlichter für die zahlreichen Rombesucher waren nicht mehr länger die römischen Altertümer und deren antiquitas. Stattdessen bildeten die Kirchen und deren Reliquienschätze die Blickfänge der Pilger. Diese neuen Schauplätze wurden in der zum anno santo gedruckten Traktatliteratur sowie in den Pilgerführern als die eigentlichen Pilgerziele stilisiert. ${ }^{681}$ Indem das Zeremoniell der Osterwoche die Reliquien der beiden Apostel-

680 Martin, Roma Sancta, S. 52-53.

681 Pientini, Pie Narrationi, S. 300-301: „Grand'obligo habbiamo noi altri con Dio, che si degni di conservarci ne l'ammirabil lume de la sua santa sede, e cosi farne conoscere inquanta riverenza s'hanno d'havere tutte le cose sagre, \& particolarmente le venerande reliquie de' suoi santi, \& quanto sia grande, \& empia la cecità de' moderni heretici, che se potessero havere un dito d'Aristotele, di Socrate, di Cicerone, ò di qual si voglia de' piu famosi gentili, lo legherebbeno in oro, lo terrebbono con veneratione grandissima, \& a fatica lo lascerebbero vedere, ilche medesimamente sarebbero vedere, ilche medesimamente farebbero di qualunque altra cosa, che di loro haver potessero, \& non vogliono [...] che si renda la debita priverenza a le reliquie di quelli, che sono stati grandissimi amici di Dio, \& ne la religion christiana campioni tanto gloriosi.“ Vgl. auch Alfani, Istoria degli Anni Santi, S. 335, 340-341, sowie folgende Stelle in Riera, Historia utilissima, S. 23-24: „,...] migliaia di persone dopo essere confessare, \& communicate con fervore di spirito tale, che riscaldanno tutta la Città di divotione, portando nel primo ordine delle loro processioni, belle \& grandi imagini del Salvatore, della Beata Vergine, \& delli Santi loro protettori, con un canto tanto dolce, \& melodioso, \& preghiere per loro amici, \& per tutta la Christianitàs, cosi ben dette, mescolare con l'honore, \& riverenza che facevano nelle Chiese alle reliquie di santi Martiri che impossibile è, racontare il piacere, \& contento de i Romani, \& di tutti i forestieri.“ Zum Reliquienkult vgl. allg. dann Popp 2014, S. 316-330; Scavizzi 1992, S. 9-22, 63; Andretta 1997, S. 355-376; Palumbo 1997, S. 377-403. 
fürsten Roms für die gläubigen Rombesucher enthüllte, bildete die Kirche von San Giovanni in Laterano mit den Heiligenköpfen von Petrus und Paul schlichtweg das Zentrum dieses urbanen Heilsraumes. Auch wenn im erwähnten Stich Du Péracs die Stadtvedute aus einer Vogelschau von der Petersbasilika aus dargestellt wurde, bildete das Patriarchium Lateranensis das eigentliche Zentrum der topographischen Verteilung der sieben Pilgerkirchen während des Jubeljahres 1575.

Nachdem mit der 1569 erlassenen Bulle Pius' V. der Streit um den Vorrang zwischen der Laterans- und Petersbasilika beigelegt und San Giovanni in Laterano als „Mutter und Haupt aller Kirchen“ Roms erklärt wurde, begann die Kurie sich damit auseinanderzusetzen, wie der dort beherbergte Reliquienschatz angemessen offenbart werden konnte. Die kurienzeremoniellen Inszenierungen des dort aufbewahrten Kirchenschatzes waren mit den zwischen 1573 und 1575 ausgeführten Eingriffen in den altertümlichen Bau der Lateranbasilika verbunden. ${ }^{62}$ Diese Arbeiten fingen mit den zeremoniellen Vorbereitungen zum bevorstehenden anno santo an und führten zur Errichtung einer eigenständigen Kapelle mit einem Sakramentstabernakel, in welchem die Hostie aufbewahrt wurde. Ein avviso vom 10. Oktober 1575 berichtet, dass dieses Tabernakel con gran spesa bereits angefertigt worden sei. Zum Zeitpunkt des anno santo musste daher der Aufbau dieser am nördlichen Eingang zum Chorumgang gelegenen Sakramentskapelle, die aber dann zu Gunsten der Errichtung eines neuen im Querhaus gelegenen Sakramentenaltars für das Jubeljahr 1600 im Pontifikat Clemens' VIII. abgerissen und in die Cappella Lancellotti verlegt wurde, weit fortgeschritten sein. ${ }^{683}$ Eine erst nach dem Tod Gregors XIII.

682 Die baulichen Veränderungen, die hauptsächlich das Baptisterium, die Scala Santa sowie die Basilika selbst betrafen, konnte bereits Freiberg 1991, S. 66-87 anhand der in ASR, Camerale I. Tesoreria Segreta, reg. 1300, f. 60r, 61v; ivi, reg. 1301, f. 15r, 25r, 53r, 58r, 67r, 73r, 75v, 78v; ivi, reg. 1302, f. 4v, 9r, 11r, 15r, 18r, 29v, 31r, 32r, 34v, 36r, 46v, 48v, 50v, 52r-v, 63r-v, 64r, 70r, 71r-v; ivi, reg. 1303 , f. $5 v, 6 r, 13 r, 14 v, 16 v, 18 r-v, 25 r$ aufbewahrten Aufzeichnungen rekonstruieren. Ein im Archivio Capitolare Lateranense aufbewahrter Stich hielt diese Veränderungen ebenfalls fest. Vgl. hierzu Krautheimer 1937-1977, Bd. 5, S. 49; Fleury 1877, Tafelband, Taf. 5. Einzelne Elemente dieses Stiches fanden Eingang in einen nun in BVR, G 21, f. 334r aufbewahrten und später zu datierenden Stich, der wohl im Zusammenhang mit Contini/Severano, Memorie sacre delle sette chiese, I, S. 534-535 entstanden sein musste. Vgl. zu dieser Darstellung auch Lauer 1911, S. 64, 313. Zur mittelalterlichen Architekturkonstellation der Scala Santa zuletzt Horsch 2003, S. 524-532.

683 BAV, Urb. lat. 1044, f. 599r. Vgl. hierzu Pastor 1893-1933, Bd. 9, S. 801; Freiberg 1991, S. 77-79; Lauer 1911, S. 318-319; Ciappi, Compendio, S. 7-9. Der päpstliche Besuch des Laterans wurde ebenfalls in Maffei, Annali, I, S. 150-151 festgehalten. Vgl. weiter auch Francisco del Sodo, Compendio delle Chiese, in BVR, G 33, f. 36v: „Ve un altare dove si conserva il santis.o Sacrame.to qual è molto ben adornato per la santita di Papa Gregorio XIII. in prima un bellissimo tabernacolo di legnio intagliato dorato e colonne di pietra fine grande e vi sono attorno al altare belli marmi con una simile balustrata assai bella qual altare fu consecrato l'anno 1580. alli 12. di marzo et in questo giorno ve indulgentia plenaria.“ Vgl. dann auch Pientini, Pie Narrationi, S. 31. Zum Aufstellungsort der Sakramentskapelle in San Giovanni Laterano vor den Eingriffen des Boncompagni-Papstes vgl. Panvinio, De basilica Lateranensis, in Lauer 1911, S. 438; idem, De praecipuis urbis Romae, S. 124; Albertini, Opusculum in Valentini/Zucchetti 1940-1953, Bd. 4, S. 498; Mariano da Firenze, Itinerarium, S. 37-38. 
gedruckte Radierung Marc Antonio Ciappis zeigt den Altar der Sakramentskapelle innerhalb einer gewölbten Architektur, die von zwei Kapitelsäulen gestützt wird (Abb. 23). Die Ädikula des Tabernakels schmückten freistehende Skulpturen des auferstandenen Christus auf der Spitze mit zwei Engelsfiguren, für die der Bildhauer Giovanni Battista della Porta beauftragt wurde. Das von Francesco da Volterra aus Holz angefertigte Tabernakel stand im Zentrum dieser Tempelarchitektur. ${ }^{684}$

Bislang fehlte es innerhalb der Forschung an einer hinreichenden Erklärung dafür, weshalb sich die Einweihung der Sakramentskapelle in San Giovanni Laterano um fünf Jahre verzögerte. Spätestens ab 1569 bekam das patriarchum Lateranensis wieder einen bedeutenden Stellenwert in der urbanen Heilstopographie Roms zugewiesen. ${ }^{685}$ Eine bislang noch gänzlich unbeachtete Schrift Francesco Mucanzios, die der Zeremonienmeister bereits 1573 in der Druckerei Antonio Blados herausgeben liess und in welcher er sich den Bildern (imaginis) der beiden Apostelfürsten Roms widmete, scheint Aufschluss über die verzögerte Instandsetzung der Sakramentskapelle in der Lateranbasilika zu geben. Mucanzios De sanctorum Apostolorum Petri et Pauli imaginibus gliedert sich in eine nachkonziliare Traktatliteratur ein, in der die umstrittene Problematik der Theologie der Bilder angesprochen wird. ${ }^{686}$ In seinen Pie Narrationi hielt Angelo Pientini fest, dass die Reliquienbüsten der Apostelfürsten Roms an Gründonnerstag, am Tag der Wiederauferstehung, an Weihnachten um am Feiertag der dedicatio der Lateranbasilika vorgeführt wurden. Francesco Mucanzios Traktat kann daher im Zusammenhang mit dieser besonderen Art einer rituell vollzogenen „Genugtuung“ (sodisfazione) gegenüber den Rombesuchern be-

684 ASR, Camerale I. Tesoreria Segreta, reg. 1301, f. 58r, 78v \& ivi, reg. 1302, f. 29v. Zu diesen Zahlungsbelegen sowie zum toskanischen Bildhauer vgl. Marucci 1989, S. 267, 273; DBI 1989, Bd. 37, S. 184; ibid. 1976, Bd. 19, S. 189-195; Freiberg 1991, S. 76. Zu della Portas Beteiligung vgl. die entsprechende Zahlung vom 11. März 1576 in ASR, Camerale I. Tesoreria Segreta, reg. 1303, f. 56v; DBI 1989, Bd. 37, S. 183-188, 185. Die Überführung der 1600 abgerissenen Kapelle wird in einem am 7. April 1601 ausgeführten saldo in ASR, Camerale I, Giustificazioni di tesoreria, b. 25, reg. 11, f. 2r erwähnt.

685 Die Einweihungsbulle zur Sakramentskapelle befindet sich in BAV, Vat. lat. 8035, II, f. 159r160r: [...] Tanta honoris excellentia excogitari non potest ut digne valeat Santissimum Eucharistiae Sacramentum venerari, quatenus tamen imbecillitas nostra patitur imminente eius Divinitatis Cultu ubique, praecipue verso in nostris maioribus Ecclesijs conservando, atque augendo facultatem nobis ex alto concessam devoto animo exercimus. Etenim eum pridem in Ecc.a nostra S. Io. Lateranen. de Urbe Cappellam, et Altare SS.mi Sacramenti ad illud ibi adornandum et asservandum opere insigni edificanda, et instituenda Curavimus sacrisque vestibus pretiosis et alijs seppellecti [...]. Auch zit. in Lauer 1911, S. 639.

686 Einen Überblick zum literarischen Genre solcher Traktate boten jüngst Boespflug/Christin 2007, S. 242-245; Scavizzi 1992, Kap. 3; Christin 1988, S. 235-243; Feld 1990, S. 193-215; Hecht 2012, S. 20-30. Ein Exemplar von Mucanzios Traktat befindet sich in BVR, S.Bor.I.I.164. 
trachtet werden. ${ }^{687}$ Die Besonderheit an diesem Reliquienschatz lag nämlich darin, dass er nur an besonderen Tagen im liturgischen Kalender vorgeführt wurde. Es ist daher anzunehmen, dass der Zeremonienmeister Mucanzio mit seiner Schrift beabsichtigte, ein für die Petersbasilika und ihrer Reliquien gedachtes Zeremoniell zu entwerfen. Für dieses Zeremoniell sollten dem Zeremonienmeister die beiden Reliquienbüsten aus San Giovanni Laterano als Vorbild dienen.

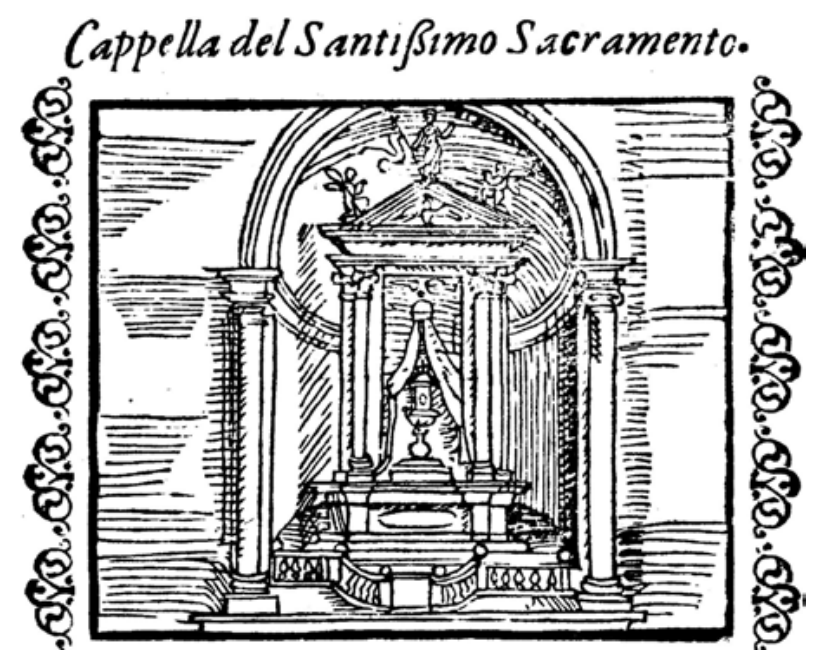

Abb. 23: Marc Antonio Ciappi, Die Sakramentskapelle im Lateran, aus: Ciappi, Compendio, S. 9.

Francesco Mucanzios De sanctorum Apostolorum Petri et Pauli widmet sich der Frage, weshalb die Bildnisbüste des Apostels Paulus zur Rechten des Apostelfürsten Petrus aufgestellt werden sollte. Den Grund eines solchen Aufbaus sah Mucanzio hauptsächlich darin, dass dadurch die Ecclesia militans als exemplum der Ecclesia triumphans betont wird. Dadurch wird eine besondere Gemeinschaft mit dem locus dignitatis, das

687 Pientini, Pie narrationi, S. 133-134: „I Canonici, \& religiose di quelle chiese, nelle quali si conservano le sacre reliquie de' santi, le mostravano loro humanamente; leggevano i nomi di ciascuna, \& con le corone loro le toccavano. In san Giovanni Laterano si scoprivano etiamdio piu volte il giorno le teste de' gloriosi Principi de gli Apostoli san Pietro, \& san Paolo, ove ne gli altri tempi non si scuoprono communemente, secondo che d'haver letto, \& in parte anco osservato, se non il giovedi santo, il giorno della Resurrezione, del Natale, \& della Dedicazione della chiesa. In san Pietro non solamente si mostra spesso il volto santo, \& il prozioso ferro della Lancia, che passò il sacratissimo costato del salvatore nostro [...] la testa di santo Andrea Apostolo, \& altre reliquie veramente mirabili [...].“ Vgl. auch Martin, Roma Sancta, S. 53 sowie Franzini, Cose maravigliose, S. 4: „Sopra l'altare Papale in quelle gratico lette di ferro, vi sono le teste delli gloriosissimi Apostoli Pietro e Paolo, \& ohno volta che si mostrano, vi è l'indulgenza di anni tre mila a gli habitanti in Roma, che vi sono presenti, \& alli convicini 6 mila, \& a quelli che vengono di lontan paesi dodici mila, \& altre tante quarantene, e la remissione de la terza parte de i peccati [...].“ 
dem Priesteramt - dem „erstgeborenen Amt“ in der Nachfolge Christi - gegenüber Gottvater als Ehrenplatz zugesprochen wird, offengelegt. Im Zeremoniell der Reliquienvorführung wird daher ein bestimmtes Bild der unauflöslichen Verbindung zwischen der Ecclesia militans und der Ecclesia triumphans hergestellt, mittels welcher die sowohl im Lukas- als auch im Markusevangelium überlieferte Episode der Vorführung Jesu vor Pilatus folgendermassen neu ausgelegt wird: Die beiden Apostelfürsten Petrus und Paulus werden als Befürworter der Königsherrschaft Christi verstanden und sind somit die göttlich eingesetzten Gegenspieler zu den beiden Vollstreckern der Kreuzigung. ${ }^{688}$ Petrus, dem ersten Apostel und Stellvertreter der Ecclesia triumphans, wird demgemäss die rechte Seite neben Christus zugewiesen. Der Apostel Paulus, der die Ecclesia militans verkörpert, steht rechts neben dem Apostelfürsten. Dem Zeremonienmeister Mucanzio zufolge sollte dieselbe Aufstellung auch im Zeremoniell zum Festtag der beiden Apostelfürsten beibehalten werden. Francesco Mucanzios Abhandlung stellt somit eine Auseinandersetzung des Zeremonienmeisters mit der in Paris de Grassis' Caeremoniarum opusculum aufgeführten Frage nach der verhältnismässigen Präzedenz zwischen den beiden Apostelfürsten dar. ${ }^{689}$

Mucanzios Traktat stellt eine Abhandlung darüber dar, wie die Ecclesia Romana in der zeremoniellen Aufführung ihres Reliquienschatzes eine rituelle Zusammenführung der Ecclesia militans mit der Ecclesia triumphans vollzieht. Der Zeremonienmeister übertrug damit das bislang im ambrosianischen Ritus vertretene Gleichnis der Ecclesia

688 Mucanzio, De sanctorum Apostolorum, S. 1-2: Qui contra antiquissimum ritum collocandi imaginem beati Pauli apostoli, ad dextrum Petri apostolorum principis latus disputant, his fermè rationibus moveri solent. Nempè in ecclesia militanti ad exemplum triumphantis, ordinem esse adhibendum, ut scilicet pro cuiusq. officio, \& dignitate alius alio superior sit, praestantioremq. gradum obtineat. Constat autem dexteram partem in honore semper habitam esse, perq. eam, tum iurisdixtionem potestatem, \& fortitudinem; tum etiam potiora bona, idest gloriam, felicitatem, beatitudinem, aeternitatemq. designari. Nam, \& ab ispo ferè mundi exordio, cum sacerdotium primigenio esset annexum, id fuisse in usu videtur, ut ipsi primogeniti, praeter alias honoris praerogativas, digniorem locum apud patrem, hoc est ad eius dexteram haberent. Et post Christi adventum per duos latrones hinc inde à lateribus crucis Domini, patibulo affixos significatum fuit. Et in ipso mundi exitu idem observandum fore certum est, cum filius hominis in suae maiestatis thronos sedens, oves ab haedis segregabit, illas quidem in dextera, hos vore in laeva statione collocans. Vgl. entsprechend die Stellen in Lk 23,1-7; ibid.,33-35; Mk 15,1-4; ibid.,26-31.

689 Mucanzio, De sanctorum Apostolorum, S. 4: [...] id etiam Paris Crassus [...] quam plurimis alijs adductis rationibus comprobavit: Ceterum altius caussam pervetusti illius ritus, ut Paulus in dextro fingatur latere, investigantibus, pulcherrima in eius defensionem argumenta occurunt. Liquido enim apparet, talem usum non temere, aut fortuito irrepsisse; quinimmo ad explicanda praecipua quaedam, ac singularia sanctissima à Deo electi viri merita, \& virtutes, nostri exempli, eruditionisque gratia à maioribus nostris introductum esse [...]. Zum Inhalt dieses Kapitels aus der in BAV, Vat. lat. 5634 I enthaltenen Handschrift de Grassis vgl. v. a. Staubach 2004, S. 114; Bölling 2011, S. 183. Zu den Arbeiten Mucanzios am Caeremoniarum opusculum vgl. dann auch Dykmans 1986, S. 285, 290-291, 316-317. Einen Anstoss zur Auslegung der praecedentia Petri hatte sicherlich auch das Kapitel in Molanus, De picturis et imaginibus sacris, c. $76 v-77 v$ gegeben. 
sponsae Christi auf eine sichtbare Wahrnehmung der Ecclesia Romana, die in der zeremoniellen Vorführung des Reliquienschatzes ihre stärkste Betonung fand. Mucanzio führte deshalb sieben Gründe auf, weshalb sich dadurch zwangsläufig eine ekklesiologische Rangordnung zwischen den beiden Apostelfürsten Petrus und Paulus ergebe. Gleichzeitig wird mit dieser Hierarchie eine bestimmte Einigkeit mit dem Sakrament der Eucharistie erzeugt. Diesbezüglich stützte sich Mucanzio auf einen der Briefe des Benediktinermönchs Petrus Damiani, in welchem die Position ad dexteram Dei des Apostels Paulus als Platz der fidei sacramenta erläutert wird. Das „spirituelle Schwert“ wird dadurch mit dem Wort Gottes gleichgesetzt. ${ }^{690}$ Das Heiligenattribut des Schwertes wirkt somit als sichtbarer Ausdruck des apostolischen Predigtamtes, durch das die Verwaltungspraxis der Sakramente überhaupt erst verwirklicht werden kann. Die beiden Reliquienbüsten im ciborium über dem Hauptaltar der Lateranbasilika, die an fünf spezifischen Tagen im liturgischen Kirchenkalender den Gläubigen offenbart wurden, verliehen der Aufstellung der beiden Apostelfürsten, wie sie Francesco Mucanzio in seiner Abhandlung vorsah, den besonderen Ausdruck einer sakramentalen Heilsrealität. Die vertikale Verbindung zwischen Reliquien und Hauptaltar, an welchem die Eucharistie während der Messefeiern in der Lateranbasilika ebenfalls vorgeführt wurde, sollte als Heilsgarant für den Empfang des göttlichen Sünden- und Gnadenerlasses wirken.

Diese zentrale Heilsdynamik, die zwischen dem Eucharistie-Sakrament und den beiden sacre teste geschaffen wird, wäre aber im Zusammenhang mit der im Kurienzeremoniell vorgeschriebenen Verwaltungspraxis der Sakramente durch einen Sakramentsaltar in San Giovanni Laterano stark gestört worden. Der Hauptaltar und der Sakramentsaltar hätten im Kirchenraum nämlich eine sichtbare Unschärfe statt einer Eintracht zwischen der Ecclesia triumphans und der Ecclesia militans zur Schau gestellt. Diese Unschärfe ergab sich deshalb, weil die Lage des Sakramentsaltars im Querhaus von der zwischen dem Langhaus und dem Hauptaltar hergestellten Longitudinalachse abwich. Die in Francesco Mucanzios Traktat anzutreffende Eintracht zwischen Ecclesia triumphans und der Ecclesia militans verwies auf eine mystische Heirat zwischen der Ecclesia und der Realpräsenz ihres Reliquienschatzes. Bis zum Jubeljahr 1575 ist somit eine Phasenverschiebung zwischen römischer und ambrosianischer Liturgik bezüglich des theologischen Verständnisses der Ecclesiae sponsae Christi festzustellen. Der Zeremonienmeister Francesco Mucanzio musste sich dieser Phasenverschiebung der beiden Riten bewusst gewesen sein, wenn er in seinem Traktat die zweite Predigt des Ambrosius, die der Kirchenvater anlässlich des Festtags der beiden Apostelfürsten hielt, erwähnt. Mittels dieser Predigt erläutert Mucanzio die aequalitas gloriae zwischen den

690 Mucanzio, De santorum Apostolorum, S. 10: Non ergo immerito filius dexterae Paulus vocatur, per quem omnis gentium multitudo, quae ad dexteram Dei ponenda est ad fidei sacramenta colligitur. Accintus siquidem verbo Dei, quod est gladius spiritus, hodie quoque \& usque in finem saeculi dimicat, \& tamquam fulminea Christi manus, vibratis caelestis eloquij gladijs rigidas resitentium Deo cervices obtruncat. 
beiden Heiligen. Für den Zeremonienmeister Gregors XIII. steht diese Ranggleichheit der beiden Apostelfürsten für den „erneuerten Glanz“ der Stadt Roms selbst. Gemäss Mucanzio ist die Stadt nicht mehr länger von ihren beiden Apostelfürsten zu trennen. Diese Verbindung zwischen Rom und den beiden Aposteln Petrus und Paulus bewerkstelligte auch das Kurienzeremoniell, indem es nämlich am Festtag Petri und Pauli denselben Stadtraum als sancta civitas sacerdotalis betonte. ${ }^{691}$ Die Errichtung von eigenständigen Altären zur Aufbewahrung der Hostie und damit der Eucharistie war eine seit der Mitte des fünfzehnten Jahrhunderts anhaltende Architekturpraxis. Indem aber das Kurienzeremoniell auf der Grundlage patristischer Schriften weiterentwickelt wurde, begannen diejenigen im Boncompagni-Pontifikat Gregors XIII. errichteten Altäre allmählich einen zur kurialen Neuauslegung des Zeremoniells widersprüchlichen Brauch vorzuweisen. Bevor eine eigenständige Architektur des Altars in der Hauptkirche Roms überhaupt erst liturgisch eingeweiht werden konnte, musste sie sich zuerst in der Kirche der Apostelfürsten selbst bewähren. Im Pontifikat Gregors XIII. fing die Kurie damit an, die theologische Verteidigung einer solchen Sakralarchitektur im römischen Kirchenraum anhand eines für die Reliquienschau erarbeiteten Kurienzeremoniells genauer zu untersuchen. Damit konnte sie einen alternativen Weg gegenüber der lutherischen sowie calvinistischen Auslegung hinsichtlich der sakramentalen Verwaltungspraxis einschlagen. ${ }^{692}$

691 Mucanzio, De santorum Apostolorum, S. 17-20, hier S. 18: [...] ita etiam cum Petrum Paulo praeponimus, Pontificiae dignitatis culmen; cum verò Paulum ad Petri dextram collocamus, aequalitatem gloriae, qua ob aequalia merita ambo in caelis fruuntur, significari recte dicimus; quos (ut beatus Leo inquit) gratia Dei in tantum apicem inter omnia Ecclesiae membra provexit, ut eos in corpore, cui caput Christus est, quasi geminum constitueret lumen oculorum. De his etiam D. Ambrosius ita loquitur. Beati Petrus, \& Paulus emonent inter universos apostolos, \& peculiari quadam praerogativa, praecellunt. Verum inter ipsos quis cui praeponatur, incertum est, puto enim illos esse aequales meritis, qui aequales sunt passione, \& simili eos fidei devotione vixisse, quos simul videmus ad martyrij gloriam pervenisse, \& reliqua. [...] per quos evangelium Romae respenduit: isti sunt eius patres, verique pastores. Sub uno persequutore, pro parili virtute compassi urbem ipsam glorioso cruore martyrij Christo Domino consecrarunt: isti sunt, qui illam in hanc gloriam provexerunt, ut sit gens sancta civitas sacerdotalis, \& Regia. Dass sich Mucanzio selbst an Sirleto sowohl hinsichtlich der Predigten des Ambrosius als auch derjenigen Papst Leos d. Gr. wandte, wurde in der Vorrede zum Traktat festgehalten. Letztere Predigt wurde bereits in Brev. Rom. (MLCT, 3), S. 798 aufgeführt, sodass der Traktat Mucanzios zweifellos eine geeignete Brücke zwischen dem Bereich der liturgischen Bücher und dem Feld des Kurienzeremoniells hinsichtlich der Formulierung eines römischen Ritus zu schlagen beabsichtigte. Das spätantike Triumphbogenmosaik in Santa Maria Maggiore hatte bereits einer solchen christlichen Idee von Rom ihre Gestalt gegeben, und zwar mit einer bildkompositorischen Zusammenführung der Synagoge der Juden mit der Kirche der Heiden. Vgl. dazu Warland 2002, S. 25-42; Poeschke 2009, S. 72-73; Panvinio, De praecipuis urbis Romae, S. 235.

692 WA, I, Bd. 6, S. 508: [...] acutissime disputans, multo probabilius esse et minus superfluorum miraculorum poni, si in altari verus panis verumque vinum, non autem sola accidentia esse astruerentur, nisi Ecclesia determinasset contrarium [...]. Vgl. dann auch ibid., S. 509-512 für Luthers Auslegungen einer Konsubstantiationslehre. Im Gegensatz zu Luther sprach Calvin dann dem Sakrament der Eucharistie jegliche physische Anwesenheit Christi ab: in Calvin, Institutio christianae religionis, 
Die mit dem Kirchenschatz verbundene Theologie der indulgentiae erwies sich als ein geeigneter Ausgangspunkt, um die Architektur von Sakramentsaltären neu ausgerichtet wieder angemessen in das Kurienzeremoniell des anno santo eingliedern zu können. Die Sakramentsaltäre sollten den rituellen Vollzug einer sichtbaren Offenbarung der Ecclesia Romana gewährleisten, in welcher sich die Ecclesia triumphans mit der Ecclesia militans verschränkte. Für den Zeremonienmeister Francesco Mucanzio musste die liturgische Zelebration des Reliquienschatzes der Petersbasilika eine besondere Rolle im Kurienzeremoniell des anno santo gespielt haben, denn während der Osterfeierlichkeiten wurden sowohl das heilige Tuch der Veronika - das sudario - als auch die heilige Lanze des Longinus vorgeführt. Mucanzios Eintrag in seinem Zeremonialtagebuch hält die Nacht von Gründonnerstag fest, die auf den letzten Tag im März fiel. In diesem Eintrag erwähnt er auch, dass anlässlich des von der sodalitas der SS. Trinità dei Pellegrini e Convallescenti organisierten Pilgerbesuchs in der Cappella Paolina der Boncompagni-Papst den Besuchern erlaubt habe, indulgentiae zu erhalten. ${ }^{693}$ Der Ab-

IV, 17-18, S. 502-535. Zu den theologischen Differenzen hinsichtlich der Eucharistie zwischen den beiden Reformatoren vgl. Davis 2008, S. 19-90; Janse 2008, S. 37-69; Kaufmann 2008, S. 149-171; Mazza 1999, S. 237-243; Leppin 2014, S. 39-56; Wandel 2006, S. 94-207. Dass diese theologischen Unterschiede innerhalb der römischen Kurie bekannt waren, kann v. a. anhand der Auseinandersetzungen des Calvinisten Andreas Volanus mit den Jesuiten Francisco Torres und Antonio Possevino dargelegt werden. Petrus Skarga hatte ebenfalls 1575 seine Pro sacratissima eucharistia zum Abschluss gebracht, auf welche sich die Polemik Francisco Torres' Contra Volanum tractatus stützte. Der Erstdruck dieser Polemik erschien 1575 in Florenz, auf welchen ein Jahr später eine zweite Auflage in Rom folgte. In Bezug auf die Notwendigkeit der Sakramentsaltäre in Kirchenräumen vgl. Skarga, Pro sacratissima eucharistia, S. 224-350 und die Stelle bei Torres, De Sanctissima Eucharistia, S. 7: Sic enim est apud vos Christus in Sacramento tanquam in signo tantum, sicut apud Iudaeos in Manna, \& sicut ille typus vetus ex Manna, \& Christus solum signifacto constabat, sic tuum Sacramentum ex pane, \& corpore Christi solum significato constat; \& sola fide percipi tradis, quam Iudaei quoque adhibeant. [...] illis vero antiquis Manna cum sua typica significatione, quanquam eandem fidem,quam nos haberent, exhibere non poterat, quia nondum Christus venerat; ergo hoc saltem concedis, quod ut illis Manna, Manna tantum erat, sic vobis panis in altari verbis domini consecratus reipsa panis tantum est, quare ut modo dicebam, tuum sacramentum merum signum est re vacuum, instar Manna Mosaici, quae illi cibum levissimum [...]. Vgl. auch ibid., S. 33-34: [...] opus erat omnipotentia ad dandum signum, \& figuram tantum corporis \& sanguinis sui? Si tu nullum miraculum ibi pateris, ne ordo naturae cuius es studiosius patronius, mutetur, \& leges eius violentur, quid igitur isto proemio opus erat sciens Iesu, quia omnia dedit ei pater in manus? Significat enim ut dixi, hoc, omnia, quaecunq. vellet, facere posse, sicut Deus pater, siquidem manus est symbolum potestatis, hic pertinet, quod per Apostolicam traditionem accepit ecclesia catholica, ut dicat sacerdos ad altare operaturus verbo domini idem sacramentum, qui pridie quam pateretur, accepit panem in sanctas, ac venerabiles manus suas, \& elevatis oculis in caelum ad te Deum patrem omnipotentem, quod quidem eadem mente, \& proposito dicit, qua evangelista dixit hic sciens Iesu, quia omnia dedit ei pater in manus. Zusammenfassend $\mathrm{zu}$ den Kontroversen zwischen Volanus und den Jesuiten vgl. Daugirdas 2008, S. 98-135.

693 BAV, Chig.L.II.30, f. 316v-317r: Nocte adveniente sodalitates laicorum incenerunt procedere ad visitanda Sepulchra S.mi Sacram.ti praecipuae illus quod in Paulina Cappella sumptuosè ornatum 
lasserwerb entfaltete sich somit mittels einer dynamischen Akkumulation des kirchlichen Gnadenschatzes, dessen Platz im Kurienzeremoniell zwischen der Verehrung des Heiligen Sakraments der Eucharistie und der zeremoniellen Reliquienenthüllung bestimmt wurde. Diese spezifischen indulgentiae, die im Palazzo Apostolico sowie in der Basilika des Apostelfürsten empfangen werden konnten, standen in einer besonderen Nähe zum Eucharistie-Sakrament. Innerhalb des Apostolischen Palastes wurde dieses Allerheiligste Sakrament, das den wesensverwandelten Körper des Leibes Jesu enthielt, innerhalb eines für die Aufführung des Sepulchrum Christi entworfenen apparato feierlich demonstriert. Mit der daran anschliessenden Reliquienvorführung in der Petersbasilika ergab sich im Kurienzeremoniell dann eine sichtbare Erweiterung (ostensio) dieser sakramentalen Heilskraft der visitatio Sepulchri. Indem die beiden Passionsreliquien des Tuches und der Lanze als Momente der commemoratio Passionis präsentiert wurden, fielen sie mit dem Heilsversprechen der Auferstehung zusammen. ${ }^{694}$ Das Kurienzeremoniell bot daher nicht nur einen günstigen ästhetischen Rahmen, innerhalb dem sich das Heilige Sakrament der Eucharistie in einer eigens dafür

erat acquirendae Indulgentiae gratia, quam Pontifex ipsis visitantibus concesserat. Fuit autem admiratione digna multitudo, et copia civium, et peregrinorum comitantium, praecipuo cum sodalitate S.me Trinitatis quae sola ultra sex milla peregrinos conduxit. Quibus omnibus in Basilica D. Petri ostensum fuit ferrum lanceae Christi, ac velum Veronicae in quo facies Salvatoris nostris impressa est. Wie sich die Reliquiendemonstration in Pilgerführer niederschlug, zeigt die Erwähnung in Pientini, Pie narrationi, S. 167; Riera, Historia utilissima, S. 70-71; Panvinio, Le sette chiese, S. 56; Zini, L'anno santo, c. $165 \mathrm{v}$ sowie dann später Alfani, Istoria degli Anni Santi, S. 335. Vgl. in Bezug auf die Pilgerführer dann Kat. Roma 1984, S. 106; Casper 2013, S. 44-47. An dieser Stelle muss noch der Umstand genannt werden, dass aus Mucanzios Einträgen für die diesem Ereignis vorangehende Zelebration der Matutin nach der Verkündigung der Bulle In Coena Domini eine deutliche Einbindung der Mitglieder der seit 1572 einberufenen Zeremonialkongregation hervorgeht. Vgl. hierzu BAV, Chig.L.II.30, f. 316r-v: Fimbrias anteriores vestis Pontificis non Protonotarij, sed Cubicularij Assistentes sublevarunt, quod ita imposterunt servandum esse Ill.mi Domini Card.les Deputati ad Reformationem Caeremoniarum cum Pontifex non gerit Pluvialo, mitramq. statuerunt. Cetere more solito. 694 Das Zeremoniell des Pilgerbesuchs des Grabes Jesu in der Cappella Paolina, welches im nächsten Abschnitt noch eingehender in Bezug auf Cesare Baronios Einbindung in die kurialen Ausgestaltungsprozesse des städtischen Heilsraumes zu untersuchen sein wird, barg ebenfalls bestimmte Assoziationen mit der funktionalen Auffassung des Papstamtes als Nachfolger der beiden von Christus ernannten Apostelfürsten Roms, da die Cappella Paolina als Ort fungierte, in welchem sich das Kardinalskollegium zum Konklave anlässlich der Papstwahl versammelte. Vgl. zu diesem Aspekt Kuntz 2008, S. 90-91. Seit Agostino Patrizi Piccolominis Caeremoniale Romanum wurde der ritus eligendi per viam scrutinii verfahrenstechnisch als Opfergabe verstanden. $\mathrm{Zu}$ diesem Aspekt vgl. insbes. Wassilowsky 2010, S. 54-62; Angenendt 2004, S. 90-92 zur Papstwahl als offertorium. Unmittelbar nach seiner Wahl wurde der neue Papst auf der sedia gestatoria in die Petersbasilika getragen. Dort angelangt, wurde er ein weiteres Mal vor dem Hochaltar der Kirche, unterhalb welchem sich die Überreste der beiden Heiligen und Apostel Petrus und Paulus befanden, inthronisiert. Vgl. hierzu den Eintrag Mucanzios in BAV, Chig.L.II.30, f. 6v-9r. Zur Papstwahl Gregors XIII. 1572, welche nach nur wenigen Stunden erfolgte, vgl. Herre 1907, S. 237; Pastor 1893-1933, Bd. 9, S. 9; Wassilowksy 2010, S. 94-95. 
errichteten Architektur zusammen mit dem Reliquienschatz offenbaren liess. Im rituellen Vollzug der Reliquienvorführung wurde nämlich gleichzeitig die Heilsrealität der Sakramente als indulgentiae selbst präsentiert. Der Erwerb verschiedener indulgentiae, wie sie vom Kurienzeremoniell während des gesamten Jubeljahres bestimmt wurden, verlangte aber eine Erweiterung des Kurienzeremoniells über die Grenzen von dessen herkömmlichem Verständnis der Messefeier, wie es die Tridentiner Abendmahlstheologie vorschrieb. Der Kurie gelang es damit, den urbanen Stadtraum Roms zu einer Heilsanstalt des Ablasses und des Gnadenerweises umzuwandeln.

Die heilsspendende Dynamik der Sakramente und ihrer Verwaltung wurde nun im Kurienzeremoniell auf den Reliquienschatz der Ecclesia Romana übertragen. Diese Übertragung bedeutete, dass die Sakramente und ihre kuriale Verwaltungspraxis mit der zeremoniellen Verwirklichung des christlichen Heilsversprechens im nachtridentinischen Rom in Übereinstimmung gebracht wurden. Das im Kreuzes- und Messopfertod Christi enthaltene Heilsversprechen konnte aber erst dann durch die Ansammlung verschiedener Formen von indulgentiae verwirklicht werden, wenn die im Sakrament der Eucharistie einverleibte Heilswirklichkeit des Opfertodes Jesu sichtbar in den Kirchenraum selbst überführt wurde. Nachdem am 12. Februar 1578 das wundersame Bild der Madonna del Socorso in der Petersbasilika mitsamt einer Prozession in die nördliche Eckkapelle, der Cappella Gregoriana, feierlich überführt wurde, konnte im Kurienzeremoniell auch die weiterführende Verschränkung zwischen dem Heiligen- und Kirchenschatz Roms und der sichtbaren Heilsrealität der sakramentalen Verwaltungspraxis angebahnt werden. Obwohl das anno santo eine solche Verschränkung einleitete, konnte sie sich nicht vollständig innerhalb des Kurienzeremoniells verwirklichen. Die fundamentale Charakteristik eines spezifisch römisch konnotierten Zeremoniells, in welchem sich die imago Ecclesiae offenbarte, lag in einer eigenartigen Unterscheidung zwischen sakramentaler Heilswirklichkeit und heilsversprechender Sichtbarwerdung begründet, die immer noch beibehalten wurde. Das anlässlich des anno santo ausgearbeitete Kurienzeremoniell konnte diesen Unterschied deutlich verkleinern. Allerdings gelang es der Kurie nicht, die Sakramente vollständig mit deren Sichtbarkeit zusammenzuführen, da der Reliquien- und Kirchenschatz nur bedingt als Behälter einer solchen sichtbaren Heilskraft der Sakramente verwendet werden konnte. Indem die Kurie in ihrer Verwaltung der Sakramente diese eng mit dem Zeremoniell der Reliquienvorführung verband, stellte sie gleichzeitig eine zentrale Bedingung auf, welche die Kirchenhistoriographik zu erfüllen hatte. Die Kurie fasste die Aufgabe des Verfassens einer Historia Ecclesiastica nämlich als eine Arbeit auf, bei der liturgische officia entworfen und gleichzeitig geprüft wurden. Diese Tätigkeit sollte dann exemplarisch mit dem Kurienzeremoniell und dem in Rom aufbewahrten Kirchenschatz vereinbart werden. 


\subsection{Das Spektakel der Quarant'ore}

Ut ostenderet tibi quod non in solo pane vivat homo sed in omni verbo quod egreditur ex ore Domine.

Der Zeremonienmeister Francesco Mucanzio warf mit seinem Traktat somit die entscheidende Frage auf, inwieweit das Kurienzeremoniell im Stande war, den urbanen Stadtraum zu erfassen und ihn anhand spezifischer Bestimmungen zu einer Theaterbühne des Heils umzuwandeln. Das Kurienzeremoniell stellte für den Zeremonienmeister ein Mittel zur Annäherung der Reliquienschau an die wundersame Heilswirklichkeit des Sakraments der Heiligen Eucharistie dar. Dadurch konnte im Kurienzeremoniell eine ostensio des im Kreuzes- und Messopfer Christi enthaltenen Heilsversprechens bewerkstelligt werden. Die Reliquienvorführung und die Realpräsenz der Eucharistie ergänzten sich gegenseitig, weshalb der Apostolische Palast mitsamt dem urbanen Stadtraum zum eigentlichen Ort der göttlichen Heilserfüllung erklärt werden konnte. Im Kurienzeremoniell wurden diese beiden Dimensionen der sichtbaren Heilswerdung allmählich zusammengeführt. Diese Annäherung erlaubte es, innerhalb des römischen Stadtraumes die Auffassung aufrechtzuerhalten, dass nicht nur den Rombesuchern, sondern auch der römischen Stadtgesellschaft selbst der Aufbewahrungsort des Allerheiligsten Sakraments für vierzig Stunden zugänglich war. Diese quarant'ore betonten eine besondere Andachtspraxis gegenüber dem ausgestellten Sakrament der Eucharistie. Die quarant'ore waren als Gedenken an die Zeit Christi nach der Kreuzigung gedacht (Lk 23,54-55), für die eine entsprechende Liturgie auszuarbeiten war.

Unter den römischen Bruderschaften betätigten sich die Mitglieder der Confraternita della SS. Trinità dei Pellegrini e Convallescenti erstmals an der Ausgestaltung einer solchen Liturgie der quarant'ore. Deren officium sollte am nachhaltigsten die übrigen liturgischen Andachtsformen der quarant'ore innerhalb einzelner Bruderschaften Roms prägen. Der englische Pilger Gregory Martin bewunderte diese Bruderschaft wegen ihrer Fürsorge gegenüber Pilgern, für welche sie Prozessionen organisierte, bei denen die Rombesucher das in der Cappella Paolina ausgestellte Sepulchrum Christi in der Nacht von Gründonnerstag besuchen durften. ${ }^{695}$ Bereits

695 Martin, Roma Sancta, S. 205: „The Companie of the Trinitie is that which for renowmed charitie thereof in the last yere of Jubilee is called La gloriosa, the glorious Compagnie. [...] They goe to Confession and receave the B. Sacrament every Moneth; and afterward goe in solemne procession with the said Sacrament, and make continual prayer for the space of 40 houres before the B. Sacrament set forth with al glorious furniture upon the altar. Which is so solemne a custome among the Confraternities, that it is knowen and renowmed by this terme Quarantae horae." Eine der weiteren römischen Bruderschaften, welche die quarant'ore um die Entstehungszeit der SS. Trinità ebenfalls praktizierten, war die Confraternita dell'Orazione e Morte, welche in engem Kontakt mit dem Kapuzinerprediger Giuseppe da Fermo diese Andachtspraxis in S. Lorenzo in Damaso förderte. Vgl. hierzu 
während des Carafa-Pontifikats Pauls IV. standen die Bruderschaften Roms in einer gegenseitige Konkurrenz bei der Aufführung eigener apparati, die sie für das vierzigstündige Gebet während der Karwoche in ihren Kirchen aufstellten. Wie die 1559 anonym verfassten Avvisi delle cose nuove successe in Roma eindrücklich festhielten, kam keiner dieser apparati jedoch demjenigen Giacomo della Portas in der Cappella Paolina gleich. ${ }^{696}$ Die römischen Bruderschaften fingen daher an, einen zentralen Stellenwert innerhalb eines noch auszugestaltenden officium für das vierzigstündige Gebete vor der zeremoniell enthüllten Grablege Christi einzunehmen. Die einzelnen confraternite orientierten sich zunehmend an den von Giacomo della Porta entworfene und in der Cappella Paolina ausgestellten apparato. Als damit begonnen wurde, mittels des Kurienzeremoniells Bruderschaften in die eigene Prozessionskultur der Kurie aufzunehmen, wurde den römischen sodalitates ein neuer Stellenwert zugeteilt. ${ }^{697}$ Die quarant'ore stellten somit rasch ein liturgisches Arbeits- und Aufgabenfeld dar, in welchem die städtische und von den römischen Bruderschaften gewahrte Prozessionskultur mit derjenigen der Kurie in Übereinstimmung $\mathrm{zu}$ bringen war. Der wichtigste Kurienprälat, der die Ausarbeitung einer solchen Liturgie zum vierzigstündigen Gebet förderte, war zweifelsohne der Mailänder Bischof und Kardinal Carlo Borromeo, denn seine eigene Auffassung der quarant'ore war mit der innerhalb römischer Bruderschaften praktizierten Andacht vereinbar. $\mathrm{Zu}$ einer sorgfältigen Ausführung des vierzigstündigen Gebetes im Zusammenhang mit der Sakralarchitektur trugen die 1577 gedruckten Instructiones fabricae et supellectis Carlo Borromeos bei. Sie stellen eine Synthese der Avvertenze per l'oratione delle quaranta hore, die während der vierten mailändischen Provinzialsynode verabschiedeten wurden, dar. Es lohnt sich daher an dieser Stelle, das vierzigstündige Gebet unabhängig von seiner ,anti-protestantische[n] Polemik“, wie sie die Forschung bislang begreifen wollte, zu untersuchen. ${ }^{698}$

Mit den quarant'ore ist eine Praxis der Andacht gemeint, die sich gegenüber anderen officia - wie demjenigen der Busse - vergleichsweise einfacher in ein zeremonielles Vokabular überführen liess. Diese Übertragung des vierzigstündigen Gebetes

dann Serra 2007, S. 80-81; EC 1953, Bd. 10, Sp. 376-378; DSAM 1986, XII/2, S. 2702-2723; Monachino 1968, S. 275-276.

696 Avvisi delle cose nuove, c. 1v-2v; Schraven 2014, S. 119-120. Die Architektur solcher apparati auch als macchine bezeichnet - sollte sich ab dem Aldobrandini-Pontifikat Clemens' VIII. mit der 1592 erlassenen Bulle Graves et diuturnae sogar noch verstärken und der Barockandacht ihre Theatralität verleihen. Vgl. hierzu insbes. Thurston 1900, S. 116-121; Noehles 1978, S. 92-116; idem 1982, S. 151-155; idem 1985, S. 88-99; Jones 2008, S. 285-291; Weil 1992, S. 680-681; Fagiolo dell'Arco 1997, S. 82-83; Noyes 2018, S. 253-263. Zur päpstlichen Instrumentalisierung der quarant'ore ab dem Aldobrandini-Pontifikat vgl. de Santi 1919, S. 265-266, 272-273, 375-380; Imorde 1997, S. 142-143.

697 Diese Einbindung von Bruderschaften in das Kurienzeremoniell hielt der Zeremonienmeister Mucanzio in seinen Tagebucheinträgen zu den Trauerfeierlichkeiten für den Herzog von Klebe fest: BAV, Chig.L.II.30, f. 302v-304v. Zum errichteten Katafalk bei diesen Trauerfeierlichkeiten vgl. auch BAV, Bonc.C.5, f. 239v-247v; Schraven 2014, S. 125-127.

698 Imorde 1997, S. 25-43; Petersen 2012, S. 115-118. 
in eine Zeremonialsprache hatte Carlo Borromeo in seinen Avvertenze folgendermassen vorgezeichnet:

Nel mettere l'Oratione, il Sacerdote, stando ingenocchiato incensarà tre volte il santissimo Sacramento, prima che lo levi fuori del tabernacolo maggiore. Poi levato fuori, si farà con esso la processione, cantandosi l'antifone appropriate. Qual processione finita, si collocarà esso santissimo Sacramento alla vista del popolo: poi si cantaranno le Letanie, preci, et orationi inginocchione. Nel levare la detta Oratione, primieramente si cantaranno le medeme Letanie, preci, et orationi: di poi finite, il Sacerdote inginocchiato incensarà come di sopra: dopo quale incensatione, si farà anco, come di sopra, la processione: et finita che sia, il detto Sacerdote benedirà il popolo con il tabernacolo minore, dove è il santissimo Sacramento: dipoi lo riporrà al loco suo nel tabernacolo maggiore, et l'incensarà come di sopra; et poi subito chiuderà il detto tabernacolo maggiore. Nelle chiese dove sarà l'Oratione, per quel spatio di tempo che si fa, non si celebri Messa o altri divini officii, ma si satisfaccia alli oblighi che vi fossero nelle chiese vicine o altre, a giudicio del Prefetto della Porta. ${ }^{699}$

In Borromeos Ermahnungen stehen die eucharistischen Litaneien, mit denen das Zeremoniell des vierzigstündigen Gebetes ausgestattet wird, im Zentrum dieser Liturgie. Jüngst versuchte Petersen anhand zweier überlieferter Litaniae de Sacrosanctae Eucharistiae, die der Kapellmeister der päpstlichen Chorkapelle Giovanni Pierluigi da Palestrina komponierte, die Frage zu beantworten, inwieweit Borromeos Anweisungen zur Rezitation solcher Litaneien innerhalb der Florentiner Compagnia dell'Arcangelo Raffaello befolgt wurden. ${ }^{700}$ Ähnlich wie im Fall der römischen Bruderschaften, welche die quarant'ore regelmässig aufführten, kann diese Frage wegen der lückenhaften Dokumentation nicht vollständig beantwortet werden. Was sich jedoch im Gegensatz zu Borromeos Avvertenze deutlich ausmachen lässt, ist der Umstand, dass die römischen Bruderschaften mit der Aufführung solcher Litaneien das Ziel verfolgten, sich von Geisselbruderschaften - wie derjenigen des Gonfalone - unterscheiden zu können. ${ }^{701}$ Eine solche Trennung einzelner Bruderschaftsgruppen bahnte sich im Rom des Boncompagni-Pontifikates nicht nur innerhalb der Compagnia della SS. Trinità dei Pellegrini e Convallescenti an, sondern auch innerhalb Filippo Neris Oratorium. In den 1578 gedruckten Statuten der Trinitäts-Bruderschaft wurde diesen liturgischen Feiern, die sich vor dem ausgestellten Sakrament der Eucharistie ereigneten, erstmals eine ästhetischzeremonielle Qualität in Hinblick auf die spirituelle Andachtspraxis der Ruhe Christi

699 AEM (1890-1897), II, Sp. 1927-1930, hier 1929. Vgl. in diesem Zusammenhang auch die beiden Schriften Luthers in WA 11, S. 431-456; ibid. 30, S. 595-626.

700 Petersen 2012, S. 121-125. In Bezug auf diese Florentiner Bruderschaft vgl. die Untersuchungen von Trexler 1974, S. 200-264; Eisenbichler 1998, S. 123, 163-166, 235-236; Hill 1979, S. 110-112; Østrem/Petersen 2008, S. 201-242. Die beiden in den 1770er Jahren für die Salzburger Kathedrale komponierten und aufgeführten litaniae de venerabili altaris sacramento Wolfgang Amadeus Mozarts ermöglichten es der musikwissenschaftlichen Forschung, einen Prototyp der modernen Opernaufführung in solchen Litaneien erkennen zu können. Vgl. diesbez. Schmid 2006, S. 73-76; Rosenthal/Mendel 1941, S. 433-455; Marx-Weber 2006, S. 201-220.

701 Eisenbichler 1998, S. 128-137, 142-143; Petersen 2012, S. 187-209. 
im Grab beigemessen. Diese zeremonielle Ästhetik der quarant'ore kam in der Gesangsrezitation sowohl bei den Litaneien der Jungfrau für die Matutin als auch derjenigen der sieben Psalmen besonders zum Ausdruck:

Et essendo l'Oratione delle Qaurant'hore per commemoratione della sepoltura del Sig. \& che debba incominciare nel medesimo giorno dell'ordinaria communione del mese, accioche alla detta oratione siano meglio i Fratelli preparati scondo il detto del Sapiente [...] Ogni mese per mano del Regente si farà l'estrattione de dodici Assistenti almeno, quali tutta la notte à sei per notte staranno ad assistere nella Chiesa, ove sarà il santissimo Sacramento fuori scoperto, \& li sei si divideranno d'ordine del Regente in due parti [...] Le due sere, che il santissimo Sacramento starà sù l'Altare, si reciterà la prima sera co'l debito modo il Matutino della Madonna, \& la seconda li sette Salmi [...] \& a questo doveranno li medesimi Fratelli del numero ritrovarsi presenti per util proprio, \& per maggior' edificatione del prossimo. ${ }^{702}$

Der bereits in San Girolamo della Carità ansässige Beichtkreis Filippo Neris erkannte im musikalischen Gesang ein geeignetes Instrument sowohl zur Aufrechterhaltung des spirituellen Lebens als auch zum „göttlichen Erwerb“ neuer Mitglieder. In der Tat wurde mit der Drucklegung von Giovanni Animuccias ersten laudi spirituali der musica sacra dem Gesang eine besondere Bedeutung innerhalb dieser Priesterversammlung eingeräumt. Filippo Neri entschied sich bewusst dafür, seine eigene Florentiner Kindheitserfahrung mit der Sakralmusik in die Andachtspraxis für seine Mitbrüder einzubringen. Später sollte dadurch das Oratorio piccolo mit dem Oratorio grande verbunden werden. ${ }^{703}$ Diese besondere Form der Andacht, welche sich aus einer musikalisch-ästhetischen Verehrung des Eucharistie-Sakraments speiste, schlug somit innerhalb von Filippo Neris engstem Beichtkreis erste Wurzeln auch in Bezug auf die quarant'ore. Mit der päpstlichen Anerkennung des Oratoriums als Priesterkongregation begannen die Oratorianer ihre Niederlassung in der Val-

702 Statuti SS. Trinità dei Pellegrini e Convallescenti, S. 50-53. Vgl. hierzu dann O’Regan 1995, S. 25-34 sowie das vom 23. Dezember 1573 in ASR, SS. Trinità dei Pellegrini e Convallescenti, Decreti di Congregazione, b. 5, f. 17v überlieferte Dekret: Facta propositione per Reverendo Padre Primicerius, fuir resolutum quod per dicendum quotidie Litanias in oratorio, extrahat qualibet ebdomada viginti confratres quod debeat intervenire quolibet sera ad dicendum dictas Litanias. Die Gesangsrezitation innerhalb anderer römischer Bruderschaften, wie der des Gonfalone oder des SS. Crocifisso, fanden entweder nur innerhalb von Prozessionen oder in den eingerichteten Oratorien statt und standen damit dem venezianischen Vorbild der scuole grandi nahe. Die Bruderschaft der SS. Trinità weihte ebenfalls am 7. April 1570 das von Vignola konstruierte Oratorium ein, was in einem weiteren Dokument aus ASR, SS. Trinità dei Pellegrini e Convallescenti, Decreti di Congregazioni, b. 2, f. $88 v$ überliefert ist.

703 Simoncelli 1974, S. 51; Abbamondi 1995, S. 133; Bella 2006, S. 186-187; Bonadonna Russo 1997, S. 46-47, sowie die Passage aus Razzi, Libro primo, c. 2: „Molte di quelle arie antiche del libro nostro ad arie moderne e più vaghe; hanno seguitato i reverendi Padri dell'Oratorio di Roma.“ $\mathrm{Ab}$ 1560 begannen der Grossherzog von Florenz, Cosimo I de’ Medici, und der Erzbischof Antonio Altoviti damit, das Vermächtnis Savonarolas wieder aufzubauen. Vgl. hierzu insbes. Van Veen 2006, S. 163; Comerford 2017, S. 36-37. 
licelliana ab 1577 sogar zur Druckerei umzugestalten und die Druckerlaubnis für Animuccias Terzo libro delle laudi spirituali bei Antonio Blado zu erhalten. Die Oratorianer übten während des Jubeljahres 1575 in Bezug auf die Feiern der quarant'ore eine besondere Anziehungskraft auf die in Rom eintreffenden Pilger aus. Zudem bot das vierzigstündige Gebet für Sänger und Komponisten wie Giovanni Animuccia und Francesco Soto de Langa ein geeignetes Karrieresprungbrett an, wodurch sie sich Eintritt in die päpstliche Sängerkapelle - der Cappella Julia - verschaffen konnten. Die laudi spirituali behielten in San Girolamo della Carità stets ihre Bedeutung als ein identitätsstiftender Mechanismus des von Filippo Neri gegründeten Beichtkreises, weshalb sie ab 1574 auch in San Giovanni dei Fiorentini eingesetzt wurden. Die dort tätigen Oratorianer Francesco Maria Tarugi, Giovanni Francesco Bordini und Cesare Baronio scheinen aber bei der Ausübung ihres Priesteramtes von diesen laudi spirituali nicht entscheidend beeinflusst worden $\mathrm{zu}$ sein. ${ }^{704}$ Stattdessen sollte sich in San Giovanni dei Fiorentini ein Umfeld von Oratorianern etablieren, die gegenüber dem Kurienzeremoniell und seinen Bestimmungen zur Andachtspraxis im städtischen Raum besonders aufmerksam wurden. Cesare Baronio war selbst eine wichtige Gestalt in dieser Unterscheidung zwischen Neris Beichthaus in San Girolamo della Carità und der ersten Oratorianerkirche, da er sich stark an der Gestaltung kuriennaher Andachtspraktiken durch die Priesterversammlungen in San Giovanni dei Fiorentini beteiligte.

Am 15. April 1574 fand in der Nationalkirche der Florentiner die feierliche Einweihung eines neuen Raumes, der für die täglichen Sitzungen der Oratorianer bestimmt war, statt. Anlässlich dieser Einweihung hielt Giovanni Francesco Bordini eine Predigt. In Bordinis überlieferten memorie lässt sich ausmachen, dass der Oratorianer sich immer noch um die Aufrechterhaltung einer bestimmten Nähe zu San Girolamo della Carità bemühte. Allerdings verfolgten die in San Giovanni dei Fiorentini ansässigen Oratorianer das Ziel, sich stärker an die Kurie anzubinden, statt ihre Nähe zu Filippo Neris Beichtkreis aufrechtzuerhalten, indem einzelne dieser Priester, wie Francesco Maria Tarugi, in sogenannte uffici vacabili des päpstlichen Behördenapparates eingesetzt wurden. ${ }^{705}$ Es ist entscheidend, an dieser Stelle zu

704 Aus der Vita Paolo Aringhis in BVR, O 58, f. 63v lässt sich Baronios Umgang mit den laudi spirituali sowie der musica sacra rekonstruieren: „Biasimava il soverchio canto de’ musici ne’ giorni festivi al vespéro, volendo che i sacerdoti cantassero solito a dire: spetta a voi altri sacerdoti il lodare e benedire il Signore e perciò cantato un mottetto no voléa che i musici cantassero più. “ Vgl. Calenzio, Vita, S. 407; Finocchiaro 2005, S. 102. Zu Animuccia vgl. dann die Zeugenaussage Bordinis in Primo Processo, III, S. 392 sowie die Untersuchungen von Piéjus 2013, S. 111-115. Hinsichtlich der Anziehungskraft der laudi an Festtagen vgl. dann insbes. Martin, Roma Sancta, S. 74, 96-97.

705 Der Familiare Carlo Borromeos, Francesco Maria Tarugi, wurde vom Kardinal Contarelli zum cavaliere di S. Pietro, zum presidente dell'anona dell'Urbe und zum porzionario di Ripa ernannt. Vgl. Cistellini 1989, Bd. 1, S. 167-168; Moroni, Dizionario, Bd. 87, S. 70-102; Del Re 1998, S. 443. Zur Einweihungsfeier des neuen Raumes in San Giovanni dei Fiorentini vgl. Bordini, Philippi Neri religiossimi viri, in ACR, A.IV.15, f. 190r: Ut autem Oratorii exercitatio commodius fieri posset, neque 
betonen, dass Cesare Baronio selbst bislang eine rätselhafte Rolle innerhalb dieser Priestergruppe in San Giovanni dei Fiorentini eingenommen haben musste. Abgesehen davon, dass sich Baronio von Carlo Borromeos Vorschlägen zur Verlegung der Priesterversammlungen Filippo Neris nach Mailand keineswegs überzeugen liess, lässt er sich noch weniger in diejenige Gruppe seiner Mitbrüder einordnen, die wie Bordini eine Nähe zu Filippo Neris Beichtkreis in San Girolamo della Carità befürworteten. Ab 1572 scheint der Priester Cesare Baronio erstmals aus Bordinis Schatten $\mathrm{zu}$ treten. Unmittelbar nach Bordinis Abreise nach Gaeta ergriff Baronio im selben Jahr die Möglichkeit, den in San Giovanni dei Fiorentini gehaltenen Predigten einen von Neri unabhängigen spirituellen Charakter zu verleihen. Baronio, der von Filippo Neris engsten Mitbrüdern als il clonico bezeichnet wurde, hatte für die sich an der „losen Rede“ (Eph 5, 4) - der eutrapelia - beteiligenden Melancholiker innerhalb des Oratoriums eine vom Beichtkreis unabhängige Bühne geschaffen, auf welcher diese melanconici „immer wieder neue Leistungen erbrachten“ . ${ }^{706}$

Diese Eigenprofilierung Baronios innerhalb der Priestergruppe in San Giovanni dei Fiorentini, welche sowohl die Nähe zu Neris ursprünglichem Beichtkreis als auch die Einbindung Carlo Borromeos in die weitere Entwicklung des Oratoriums befürwortete, sollte sich am deutlichsten zwischen 1574 und 1576 offenbaren. Baronio setzte sich nämlich während dieser zwei Jahre für die Aufnahme des ehemaligen Arztes Giovanni Giovenale Ancinas, der anlässlich des Jubeljahres 1575 den Botschafter des Herzogs von Savoyen nach Rom begleitete, in die Priesterkongregation der Vallicella ein. In einem Brief an seinen Bruder Giovanni Matteo, den Giovenale Ancina im Mai 1576 verfasst haben muss, erläutert der spätere Oratorianer die noch in San Giovanni dei Fiorentini stattfindenden Zusammenkünfte der Priesterversammlungen, auf die sich sein späterer Biograph Bacci ebenfalls stützte:

[...] entrò un giorno il buon Giovenale per Divina ispiratione nella Chiesa di S. Gio.de' Fiorentini, dove in quel tempo facevano gl'esercitij i Preti della Congregatione dell'Oratorio novellamente instituita da S. Filippo, e sentendo sermoneggiare, vi si fermò; E quando sentì quella maniera familiare di ministrar la parola di Dio con utilità, e semplicità, aggiuntavi quella soave terminazione della musica, rimase affetionato, e preso: e vi ritornò più volte: e seguitando di frequentare quel luogo, s'innamorò sì fattamente dell'Istituto, che desideroso di farne

quotidie ad D. Hieronimi eundum esset vel sermones habendi causa, Florentini ad ripam Tiberis egregium opus construxere, ibique sermones haberi coepti sunt.

706 ACR, P.I.1. (n. f.): „Et prima dovete sapere che si attende assai bene alla eutrapelia, et sempre li melanconici trovano qualche nova inventione. [...] Il reverendo padre messer Filippo mi ama tanto, ch'è uno stupore; tutto si gode del fatto mio, tutto teme non perdermi [...]. “ In diesem Brief bezeichnet Baronio Bordini als seinen persecutore; Tarugi selbst „ist [ihm] kein ernster Vater mehr“ (non è più padre severo). Vgl. dann auch zwei Briefe Tarugis an Bordini vom 11. Dezember 1572 und vom 28. Februar 1573 in ACR, P.I.4, f. 12r-v, resp. f. 43v, in denen Tarugi folgendes Relief Baronios an Bordini präsentiert: „[...] come è strapazzone, ve la guasta et lacera et li piange indosso [...] è destro burlone come quell'onagro che volse concorrer col setino a far carezze al padrone, et li roppe con le zampe la testa.“ 
partecipare il fratello scrisse una lettera di questo tenore. Da certi giorni in quà vado all'Oratorio di S. Gio: de' Fiorentini, dove si fanno ogni bellissimi ragionamenti spirituali, sopra l'Evangelio, delle Virtù, e Vitij, e dell'historia Ecclesiastica, e delle Vite de' Santi, \& ogni giorno sono quattro, ò cinque che ragionano, e vi vanno à sentire persone honorate, Vescovi, Prelati, \&c. alla fine si fà un poco di musica per consolare, e ricreare gli spiriti stracchi da discorsi precedenti. Hanno narata la vita del glorioso S. Francesco, e di diversi suoi discepoli, e di S. Antonio da Padova. Vi prometto, che è cosa bellissima, e di gran consolatione, \& edificatione: E mi sà male, che ne voi, ne io, non sapessimo mai l'anno passato, che ivi si facesse sì nobil esercizio. Hor sappiate che quelli, che vi ragionano, sono persone qualificate, in sacris, di molto esempio, e spiritualità. Hanno per capo un certo R. P. Filippo vecchio hormai sessagenario, mà stupendo per molti rispetti, e specialmente per la Santità della vita, e per la mirabile prudenza, e destrezza in inventare, e promovere esercitij spirituali, essendo stato autore di quella grand'opera di carità, che si faceva alla Trinità de' Pellegrini quest'Anno Santo. ${ }^{707}$

Mit den ragionamenti spirituali musste Ancina die Predigten innerhalb des Oratoriums gemeint haben. Dies lässt sich anhand eines Briefschreibens Francesco Maria Tarugis an Borromeo bestätigen, da in diesem der in San Giovanni dei Fiorentini neben Baronio und Bordini ansässige Tarugi diese ragionamenti noch als modi familiari di trattare il Verbo di Dio bezeichnete. ${ }^{708}$ Die Oratorianer von San Giovanni dei Fiorentini, deren spirituelles Zusammenleben Cesare Baronio ab 1572 intensiver zu gestalten begann, verfolgten demnach das Ziel, ihre Predigtpraxis mittels den von Ancina genannten loci weiter auszubauen. Dies wiederum bestätigt die vorhin geäusserte Vermutung, dass Cesare Baronios Annales Ecclesiastici im Zusammenhang mit einer kontroverstheologischen Auslegung der incarnatio Domini entstanden sein müssen. Zwischen 1574 und 1576 waren sie deshalb - für Baronio selbst zumindest - noch weit von einer eigentlichen Historia Ecclesiastica entfernt.

Demgemäss fällt die Entstehung von Cesare Baronios Annales, in denen von der Entwicklung der Romana Ecclesia ab der Fleischwerdung Gottes kirchenhistoriographisch berichtet wird, mit den ab dem anno santo begonnenen Bemühungen der Kurie und einzelner Bruderschaften, die quarant'ore in einem angemessenen officium auszuüben, zusammen. Carlo Borromeos Avvertenze boten eine Form, gemäss welcher

707 Bacci, Vita Ancina, S. 15-16. Ancina sagte ebenfalls 1608 anlässlich der Heiligsprechung Neris aus und erwähnte in seiner Zeugenaussage wiederum dieses Schreiben an den Bruder: Primo Processo, II, S. 308-311, hier S. 309. Baccis Biographie Ancinas setzt sich aus Zeugenaussagen zu seinem Seligsprechungsprozess, den allerdings erst Leo XIII. 1890 abschloss, zusammen. Zu Ancina, der am 10. November 1574 in Begleitung Giovanni Federico Madruzzos anlässlich des Jubeljahrs in Rom eintraf, vgl. Cistellini 1989, Bd. 1, S. 233-237; DBI 1961, Bd. 3, S. 40-43; Piéjus 2017, S. 149-172. 708 BAM, F 99inf., f. 160r-v, 160r: „[...] il quale esercitio consiste in trattare ogni giorno il Verbo di Dio con un modo familiare, ritenendo però la dignità debita [...]." Auch ediert in Marcora 1967, S. 266-269, 266. Jedoch sind Tarugi und Cesare Speciano nicht die einzigen, die Borromeo über die Versammlungen in San Giovanni dei Fiorentini informierten. Vgl. diesbez. v. a. die beiden von Bernardino Carniglia verfassten Briefschreiben in BAM, F 49inf., f. 103r-105v \& ibid., F 87inf., f. 82r-83v. Sogar Borromeo selbst hatte 1572 den Erzbischof von Lissabon über das frühe Oratorium und die in San Giovanni dei Fiorentini ansässigen Priester informiert: BAM, P 7inf., f. $422 r$. 
eine solche Liturgie der quarant'ore gestaltet werden konnte. Die Vorschriften des Kardinalbischofs von Mailand hielten fest, dass ragionamenti oder sermoni, die ,eine viertel Stunde nicht überschreiten durften“, besonders „kurz“ zu halten waren. Diese ragionamenti und Predigten waren denjenigen ähnlich, die Filippo Neri zusammen mit Francesco Maria Tarugi in Santa Maria sopra Minerva hielt. ${ }^{709}$ Wie bereits die musikgeschichtliche Forschung vielfach zeigen konnte, mussten diese Predigten, mit denen die Oratorianer eine spirituelle Andacht innerhalb des vierzigstündigen Gebets einführten, bis zu der ab 1586 begonnen Systematisierung der Priesterkongregation gemäss eines „halb-improvisierten“ Charakters der Homiletik gestaltet worden sein. Solche Homilien wurden dann mittels der Ausarbeitung der laudi spirituali in einen ästhetischen Rahmen des liturgischen Gesangs eingefügt. Dieser zeremonielle Rahmen der sermoni scheint aber auf einen zentralen Unterschied zwischen San Giovanni dei Fiorentini und San Girolamo della Carità zu verweisen. Filippo Neris engster Beichtkreis erhob den liturgischen Gesang, der hauptsächlich von Sängern der cappella giulia aufgeführt wurde, zum Kern der Predigten im Oratorium. Hingegen sahen Cesare Baronio und seine Mitbrüder in San Giovanni dei Fiorentini in diesen Predigten eine Möglichkeit, die Fleischwerdung Gottes kontroverstheologisch ableiten zu können und die Momente ihrer sichtbaren Offenbarung vorzuführen. Somit stand die in San Giovanni dei Fiorentini vertretene Ansicht in einem Gegensatz zu derjenigen, die Neri und sein Beichtkreis

709 AEM (1890-1897), II, Sp. 1929: „Si provegga anco, che vi si faccino alcuna volta, pii et affettuosi ragionamenti da persone deputate, et approvate da Noi. Questi ragionamenti siano brevi, in modo che non eccedino un quarto d'hora; et siano più tosto eccitamenti d'oratione, e come ponti di meditatione, che in forma di sermoni, nè di prediche. "Vgl. in diesem Zusammenhang die Zeugenaussage Giovanni Francesco Buccas in Primo Processo, I, S. 103-104: „Et del detto tempo 1551, quando fu principato in Roma l'oratione delle quaranta hore, esso p. m. s. Filippo praticava continuamente nella chiesa di S. Salvatore in campo, dove a l'hora faceva molto frutto, con sermoni et boni essempii, che continuamente dava; et le notte continue vegliava, et, quando quelli, che facevano oratione, entravano nell'oratione, veniva con campanello, et diceva a quelli che havevano finita l'hora: horsù, fratelli è finita l'hora, ma non quella del ben operare et ben fare." Zu Tarugis Übernahme der quarant'ore in Santa Maria sopra Minerva vgl. Marciano, Memorie historiche, I, S. 42: „[...] alla presenza di molti, disse di esser mandato da alcuno Religiosi, a' quali Iddio havea manifestato una gran cosa: indi havendsi tiratoin disparte Francesco Maria Tarugi à lui l'espose. Gli disse dunque, che ponessero l'Oratione delle Quarant'hore, poiche da quella ne sarebbe seguito gran frutto: mentre tutta quella machina, che per istigatione del demonio era stata fabricata, qual fumo al vento sarebbe svanita, e l'opra dell'Oratorio più che mai rigogliosa sarebbe fiorita [...].“ Die mit Tarugi gemeinsam durchgeführten vierzigstündigen Gebete im Konvent der Dominikaner werden ebenfalls in Bacci, Vita Neri, S. 190 erwähnt. Vgl. in diesem Zusammenhang auch Baronios eigene Bezeichnung Tarugis als dux verbi in Ann. Ecc., I, S. 477. In der kollektiven Erinnerung der Oratorianer, die sich während des Heiligsprechungsprozesses nach $1595 \mathrm{zu}$ bündeln begann, waren die quarant'ore von der Figur ihres beato Padre nicht mehr getrennt zu denken. Vgl. die Zeugenaussagen in Primo Processo, I, S. 71-72, 103-104; ibid., III, S. 85, 156, S. 253; Gallonio, Vita, S. 14 sowie die Zeugenaussage Francesco Puccis extra urbem in ACR, A.III.52, f. 33r: [...] et multoties vidi ipsum, diebus festivis, post completum Oratorum, in divi Hieronymi, pergebat ad audiendam predicationem in ecclesia Divae Mariae supra Minervam, cum magno comitatu [...]. 
in San Girolamo della Cartà vertraten. Dieser Unterschied lässt sich dadurch erklären, dass die Predigten in der Nationalkirche der Florentiner vor einem grossen Publikum, das sich vorwiegend aus der römischen Stadtgesellschaft zusammensetzte, vorgetragen wurden. Hingegen besass Filippo Neris Beichtkreis in San Girolamo noch den Charakter eines geschlossenen Priesterbündnisses, das der Stadtgesellschaft nicht zugänglich war. Die spirituellen Exerzitien in San Giovanni dei Fiorentini entwickelten sich deshalb rasch zu einem spektakulären Ereignis der frommen Andachtspraxis. ${ }^{710}$

Die Herausforderung, welche mit dieser Öffnung des Oratoriums gegenüber der städtischen Gesellschaft verbunden war, glich dem bereits in Cesare Baronios De origine Oratorii geschilderten Ausbruch aus einer „bethlehemitischen Enge“. Die ab 1575 päpstlich anerkannte Oratorianerkongregation sollte die Strategien ihrer Öffnung und die spirituelle Bedeutung der laudi spirituali als ein ästhetischer Rahmen für ihre Predigtaufführungen miteinander verschmelzen. Das anno santo bot dafür eine gute Gelegenheit, um den seit 1551 praktizierten Besuch der sieben Hauptkirchen Roms mit liturgischem Messgesang weiter auszugestalten. In diesen laudi wurden die sieben Hauptkirchen der Stadt gegenüber den Rombesuchern als Heiligtümer betont. ${ }^{711}$ Die quarant'ore stifteten in diesem Itinerarium der mirabiliae Romae eine

710 Die Schieflage zwischen den beiden Orten der Oratorianer, welche zugleich die Geburtsstunde im anno santo des oratorio all'aperto einläuten sollte, lässt sich vor allem aus den unterschiedlichen Positionen gegenüber dem problematischen Mangel eines sanctorale innerhalb der Priesterversammlung nachvollziehen. Während somit Neri an der Überzeugung, dass die laudi spirituali eine solche Abwesenheit durchaus kompensieren konnten, festhielt, zeigte die Nähe der Priester in San Giovanni dei Fiorentini zu Borromeo deutlich, dass ein solcher Ersatz nur durch eine Weiterführung der hauptsächlich aus dem neuen Breviarium Romanum abzuleitenden Homiletik bewerkstelligt werden konnte. Dies war unter anderem auch durch die zwischen 1563 und 1600 stattgefundene Drucklegung von über 400 laudi bemerkbar, worunter allerdings nur ein Zehntel Heiligenviten gewidmet war. Vgl. hierzu insbes. Piéjus 2013, S. 92-95, die jedoch m. E. die Genese der Annales sowie weiterer hagiographischer Werke Baronios fälschlicherweise einem Einfluss der laudi zuordnet. Wie sich bald zeigen sollte, hatte Baronio eine Hagiographie verfolgt, die den kurialen Vorstellungen einer Einbettung von Heiligenbiographien in das liturgische Kurienzeremoniell folgte. Vgl. hierzu insbes. infra, Kap. 7. Erst in diesem oratorio apperto fanden sich, gemäss der Zeugenaussage Della Molaras in Primo Processo, II, S. 16, auch Mitglieder des Kardinalskollegiums wieder: „Ho visto ancora venire, dal beato Filippo, spesse volte, molti cardinali: in particolare, mi ricordo avervi veduto, spesso, il card. Paleotto, il card. Alessandrino, il card. Santa Severina, il card. Borromeo giovane (Federico Borromeo); il card. Cusano, il card. Sfondrato, [...] il card. Aldobrandino, [...] il card. di Firenze, [...] il card. Paravicino e altri.“

711 Pientini, Pie Narrationi, S. 180: „Fu medesimamente tenuta molto degna la processione della reverenda congregazione dell'Oratorio, amendue le volte che andò à visitar le chiese. Imperoche havendo ottenuto grazia da Nostro Signore di conseguitare ambidue le volte il Giubileo, per esserne piu capace, \& arrichirsi piu di meriti, non solamente visitò le quattro, ma le sette, \& come vi si trovò una gran comunita d'huomini solamente, cosi vi si vidde una divozione molto singolare. Onde per tutta la strada cantavano con bell'ordine Letanie, Hinni, \& Salmi. Et poi nell'entrare delle chiese, si cantavano con voci, \& suoni molt'altre cose divote. Si fecero ancora in piu chiese serventi essortazioni.“ Vgl. auch Bacci, Vita Neri, S. 60-61 sowie die einzelnen Zeugenaussagen in Primo 
spezifische Andacht der Ruhe Christi im Grab. Carlo Borromeo bezeichnete in seinen Avvertenze die dafür errichteten apparati auch als Sepolcri, die man mit einer bestimmten custodia zu besuchen habe. Borromeo selber formulierte aber kein officium dafür, wie das Grab Christi zu pflegen sei. Vielmehr widmete er sich der Frage, wie das eucharistische Gebet und mithin dessen Altar auszustatten waren. Eine bestimmte Anzahl an Kerzen, die an diesen sepolcri angebracht wurden, rief ein Lichterspiel hervor, durch das die ehrfurchterregende Dunkelheit einen Kontrast bildete zu dem sich den Gläubigen erbarmenden Mysterium sowohl der Grablege als auch der Kreuzigung. Das Sakramentstabernakel offenbarte dabei eine imago Christi, welche die Gläubigen bei der obskuren Ausstellung der Eucharistie zu grösserer Andacht anregte. $^{712}$

Die Pilger nahmen anscheinend den Wettbewerb, der um die Gestalt des schönsten Grabes entbrannte, wahr. Der deutsche Wallfahrer und Münchner Hofprediger Johann Jacob Rabus berichtete von einer Pilgergruppe, die am Nachmittag des Gründonnerstags mit der Besichtigung aufgerichteter sepolcri begann. Er fügte hinzu, dass bei diesem Besuch „ein freundlicher Streit“ darüber ausgebrochen sei, „,welches dieser Gräber doch das schönste wäre“. Rabus selbst entschied sich für das Grab in der Spanischen Nationalkirche von San Giacomo als das „stattlichst“ ausgestattete, auch wenn „der Herrn Jesuiter Grab das andächtigst und ordentlichst wär““. ${ }^{713}$ In dieser Hinsicht bleib

Processo, IV, S. 23; ibid., III, S. 32-36, 158, 178-179, 262, 389; ibid., I, S. 385-386. Erst nachdem die ersten Dekrete verfasst wurden, entstanden die ersten gedruckten Traktate, in denen der Modo di visitare le sette chiese erläutert wurde. Diese offizielle Drucklegung des ersten Modo 1588 war hauptsächlich dem Oratorianer Antonio Talpa in Neapel zu verdanken, der bereits zwei Jahre zuvor diese Praxis der Aufnahme neuer Mitglieder sowie Teilnehmer in Talpa, Institutio Congregatio Oratorii, S. 363 grundlegend beschrieben hatte. Hinsichtlich des Einsatzes begleitender Gesänge vgl. dann O’Regan 1995, S. 57-59, 69; Piéjus 2013, S. 268-289. Zur Prozessionskultur zwischen den vier Patriarchalbasiliken in römischen Bruderschaften vgl. Pientini, Pie Narrationi, S. 144-147.

712 AEM (1890-1897), II, Sp. 1929: „[...] si facci oscura [...] per accompagnare il misterio dell’instituto di questa Oratione, et per ecitarsi più a divotione." Vgl. weiter zur architektonischen Ausstattung des Tabernakels als Aufbewahrungsort der Hostie dann Borromeo, Instructiones, S. 22-23: Quod tabernaculi opus, polite elaboratum et apte beneque inter se compactum, piis item mysteriorum passionis Christi Domini imaginibus exculptum, et inaurato artificio certis locis, periti viri iudicio, decoratum, religiosi et venerandi ornatus formam exhibeat. Intrinsecus autem tabernaculis populeis circumamictum esse debet, vel aliis eiusmodi, ut ab humiditate, quae ex metalli marmorisve genere existit, sanctissima Eucharistia illo amictu omnino defendatur. Ubi tabernaculum eiusmodi non fiat, tunc e tabulis non nuceis, vel aliis, quae himiditatem gignunt, sed populeis aut similibus polite elaboratis, et religiosarum, ut supra, imaginum sculptura ornatis iisdemque inauratis, extruatur. [...] In summo tabernaculo sit imago Christi, gloriose resurgentis vel sacra vulnera exhibentis; vel, si in altari exiguae alicuius ecclesiae per tabernaculi occupationem congruus locus cruci, quae alias super eo collocaretur [...].

713 Münchner Pilgerfahrt, S. 112-113. In diesem Zusammenhang bleibt stets der Bezug, wie das Sakrament der Busse hinsichtlich der Beichte administriert werden sollte, zentral. Vgl. hierzu dann insbes. Riera, Historia utilissima, S. 75-78: „Vi era buon numero di persone molto dotte di diverse nationi, le quali insegnavano à forestieri i punti principali della loro conscienza, accioche meglio, \& 
aber die Frage, wie die Andacht und das Gebet über das nun zeremoniell aufgeführte sepulchrum angeregt werden könnte, unbeantwortet. Weder in seinen Avvertenze noch in seinen Instructiones ging Carlo Borromeo auf die liturgischen Bedingungen, die überhaupt eine solche zeremonielle Ausstattung ermöglichen sollten, ein. Die spektakuläre Präsentation dieser Sepolcri hatte nämlich nicht zwangsläufig zum Ziel, eine Auseinandersetzung mit dem Mysterium der Auferstehung zu erzeugen. Gerade darin lag aber die entscheidende Frage, ob Elemente einer Bilderverehrung, die nicht mehr der Verehrung Christi und der Heiligen gewidmet waren, in die mit einem ästhetisch überladenen Apparat gefeierte Karsamstagsliturgie einbezogen werden sollten. In vielerlei Hinsicht unterstützten solche apparati die materielle Ausstattung des Kirchenraumes. Nicht umsonst hatte Borromeo in seinen Avvertenze eine Vorschrift darüber erlassen, welcher Schmuck anzubringen war. Der Mailänder Bischof forderte nämlich, dass solche apparati ästhetisch eine religiosa politezza („ehrfürchtige Reinheit“) präsentieren sollten. ${ }^{714}$

Den Eifer über die Theatralik der eucharistischen Verehrung, die Filippo Neri und sein Beichtkreis während des anno santo förderten, wies der Melancholiker (clonico) Cesare Baronio ab. Grundsätzlich wäre mit der Kreuzigung Christi eine Kirchengeschichte, wie sie als Modus der historia ecclesiastica innerhalb des Oratoriums im Gefüge der „losen Rede“ praktiziert wurde, bereits vollbracht worden. Das verbum Dei durchlief nämlich alle Episoden, die im christlichen Heilsversprechen enthalten waren, ab seiner Fleischwerdung bis zum Kreuzes- und Messopfertod Christi. Mit dem Ausbruch aus der „bethlehemitischen Enge“ wies Cesare Baronio gleichzeitig auf die

più religiosamente guadagnassero il santissimo Giubileo. Il numero delle confessioni era tanto eccessivo, che per attendere giorno \& notte à questo essercitio, alcuni Confessori resero l'anime al loro Redentore in questo santo, \& christiano essercitio. I Sacrarii santi, overo Sepolchri, quali sogliono apparechiarsi il Giovedì \& Venerdì Santo, per porvi il Santissimo Sacramento, erano cosi riccamente ornati, \& ciascuno s'impegnava con tal'animo in questo [...] Arrivata che fu la Pasqua, impossibil è poter scrivere il numero di quei, che ricevettero il Santissimo Sacramento del Santissimo Corpo di Christo, dopò essersi prima apparechiati mediante la santa confessione, avenga che per tutta l'Ottava infino ad un'hora dopo mezzo giorno fusse necessario dare la santissima communione à i popoli [...].“

714 AEM (1890-1897), II, Sp. 1927: „Si orni il luogo, dove si mette, con religiosa politezza, non usando moschetti, ne altri ornamenti profani, ne razzi con historie, et imagini lascive, o altriment profane. E s'orni la cappella solamente, et dove si possa comodamente, si facci oscura la detta cappella si che non habbi altro chiaro, che de i lumi [...]." Bei Giorgio Vasaris Eingriffen im Umbau der Florentiner Ordenskirchen von Santa Maria Novella und Santa Croce, während welchem die tramezzi entfernt wurden, waren solche Vorschriften gegenüber den Verschönerungsmassnahme eher zweitrangig: ,[...] tirando esso altare alquanto innanzi, e ponendovi sopra un nuovo ricco tabernacolo per lo SS. Sacramento, tutto ornato d'oro, di storie e di figure.“ Zit. n. Vasari, Vite, VII, S. 711. Diese Umgestaltungskampagnen im Florenz Cosimo I de’ Medicis bedürfen seit längerem einer neuen analytischen Betrachtung, bei welcher die Konflikte zwischen den eigenen politischen Antizipationen des Grossfürsten und den liturgischen Vorschriften seitens der römischen Kurie stärker betont werden sollten. 
Grenzen des Verständnisses einer historia ecclesiastica, die innerhalb des Oratoriums vorherrschten, hin. Indem das Kurienzeremoniell im Hinblick auf das anno santo nicht nur in San Giovanni dei Fiorentini, sondern in den gesamten Stadtraum allmählich einzudringen begann, löste sich diese Eingrenzung der Priesterkongregation als Beichtkreis ebenfalls auf. ${ }^{715}$ Diese Dynamik forderte die römischen Bruderschaften und insbesondere das Oratorium dazu auf, sich stärker mit der Frage, wie sich im messianischen Spektrum des Evangeliums das Heilsversprechen Christi im Bild der Ecclesia tatsächlich verwirklichen konnte, zu befassen. Die vita Christi allein bot noch keine angemessene Verteidigung eines universellen Anspruchs auf die sakramentale Heilsverwaltung der Ecclesia Romana, wie es die Kurie forderte. Es bedurfte daher einer kontroverstheologischen Erweiterung der Sakramentsverwaltung, die über die Grenzen des Kreuzes- und Messopfertodes Christi hinausging. In seinem bereits erwähnten Brief an den Kardinal und Präfekten der Indexkongregation Guglielmo Sirleto erklärte der Oratorianer Cesare Baronio, dass er die gesamte Kirchengeschichte „von Neuem schreiben“ wolle. Baronios Absicht zeugt vom Gefühl einer Eingrenzung, die er in seinen Predigten zur quaresima deutlich zum Ausdruck gebracht hatte und die er nun auch in Bezug auf die theatralische Aufführung der quarant'ore verspürt haben musste. Die Entscheidung, eine Kirchengeschichte schreiben zu wollen, bestätigt Cesare Baronios Ablehnung der laudi spirituali, die das Zusammenleben der Priesterkongregation weitestgehend bestimmten. Dieses Spannungsverhältnis zwischen Baronios eigenen Interessen und dem Zusammenleben der Oratorianer scheint auf die liturgische Ausgestaltung der „losen Rede“, die Baronio für die Priesterversammlungen in San Giovanni dei Fiorentini im Sinne hatte, zurückzugehen. Eine Kirchengeschichte bedeutete für den Oratorianer Cesare Baronio daher, einen Ausweg aus dieser Einengung durch Filippo Neris Förderung der laudi spirituali zu finden. Ab

715 Einen entscheidenden Beitrag leisteten die für den Grossherzog von Florenz, Cosimo I de’ Medici, in San Giovanni dei Fiorentini gehaltenen zeremoniellen Trauerfeierlichkeiten am 19. Juni 1574. Vgl. hierzu insbes. die Einträge Francesco Mucanzios in seinem Tagebuch in BAV, Chig.L. II.30, f. 239v: Celebratae fuerunt exequiae in ecclesia S. Jo. Florentinorum experosis Nationis Florentinae regio apparatu. Adfuerunt non nulli Card.les, et Praelati, et ibi intervenit Ludovicus Collega meus. Habuimus funalia elevationis Sacramenti ut moris est, ac etiam propinam decem docatos. Die Trauerfeierlichkeiten reihen sich in eine bestimmte Folge herrschaftlicher Begräbnisfeiern in Rom ein, die bereits ab der Wahl Gregors XIII. einsetzten. Wie Shraven 2014, S. 98-103 deutlich zeigen konnte, befanden sich solche Trauerfeierlichkeiten in ihrem liturgischen Stadium der Ausarbeitung noch in einer Frühphase, an welcher aber hauptsächlich sich das Kardinalskollegium beteiligte. Zur möglichen Patronage Stanislaus Hosius' für die Trauerfeier des im Juni 1572 verstorbenen Königs Sigismund Augustus II. von Polen vgl. insbes. Treter, Theatrum virtutum, c. $90 v$, wo der aufgerichtete apparato abgebildet ist. Zu den Trauerfeierlichkeiten in San Giovanni dei Fiorentini vgl. dann auch das avviso vom 26. Juni 1574 in BAV, Urb. lat. 1044, f. 113r; Bandini, Oratio in obitum Ser.mi Cosmi Medices Magnis Hetruria Ducis, in BAV, Barb. lat. 1816, f. 1r-18v sowie Le sontuose e ricche pompe, S. 3-4. 
1568 fing Baronio auch damit an, nach der „anstrengenden“ Fastenzeit nach Loreto zu reisen, wo er seine persönliche Andacht der Gottesmutter pflegen konnte. ${ }^{716}$

Cesare Baronios Suche nach einer selbständigen und von Filippo Neri unabhängigen Laufbahn im Rom Gregors XIII. lag zwangsläufig im Bereich des Liturgischen, denn in diesem war ihm Filippo Neri deutlich unterlegen. Die hilarità christiana, welche ebenfalls in der Zelebration der quarant'ore zum Ausdruck kam, hatte diesen Mangel der Ausarbeitung einer bewusst römisch konnotierten Liturgie weitestgehend kompensieren müssen. Der erste Band von Baronios 1588 gedruckten Annales Ecclesiastici ist von einer besonderen Sprache geprägt, die von seiner Abneigung gegenüber Neris ästhetisch anmutender Spiritualität zeugt. Auch wenn diese reine Ästhetik des spirituellen Zusammenlebens Baronios Mitbrüder in San Giovanni dei Fiorentini ebenfalls allmählich zu beeinflussen begann, erreichte sie erst mit der Überführung der Priesterkongregation in die Vallicelliana ihre vollständige Wirkkraft. Statt sich daher dem theatralischen Spektakel der quarant'ore zu widmen, setzte sich Cesare Baronio mit der Frage auseinander, wie die im Gedenken an das Grab Christi errichteten sepolchri liturgisch zu pflegen waren. Damit war auch die Frage, was nach der Auferstehung vom Heilsversprechen Christi für die Glaubensgemeinde noch übrig blieb, verbunden. Die sepolcri Roms, auf welche Carlo Borromeo in seinen Avvertenze bereits zu sprechen kam, lassen sich in eine bestimmte Entwicklung der jüdischen Begräbnispraxis und ihrer Überführung in einen römischen Ritus der sepultura eingliedern. In diesem rituellen Wandel wurde das Grab Christi als Vorbild für die Inszenierung der Märtyrer- und Heiligengräber betrachtet, da der biblischen Überlieferung zufolge nach der Kreuzigung der Leichnam Jesu zusammen mit den instrumenta ad mortem beigelegt wurde. Die custodia des Grabes Christi, das Joseph nach der Kreuzigung als monumentales Privatgrab aus Stein errichten liess, wurde zwei Söldnern anvertraut, welche die versiegelte Grablege hüten sollten. Demgemäss verstand Cesare Baronio das officium der Pflege der Grablege Christi als eine custodia sigillum sepulcro, die nach dem Tag der Auferstehung in eine custodia instrumenta ad mortem überging. Diese zweite rituelle Pflege des Grabes liess sich dann auch auf die Pflege der Reliquien übertragen. ${ }^{717}$

$716 \mathrm{Zu}$ diesen Pilgerreisen nach Loreto vgl. das an den Vater adressierte Briefschreiben vom 2. Mai 1568 in BVR, Q 46, f. 46v: „Io per gratia di Dio dissi la Messa nell'altare santissimo dentro la cappella della Madonna di Loreto, e vi stei dentro dove sta proprio la Madonna solo, quanto tempo volsi, gratie che si concedono a pochi.“ Die Bruderschaft der SS. Trinità dei Pellegrini e Convallescenti wird erstmals zwischen dem 14. April und dem 2. Mai 1578 ebenfalls Pilgerreisen nach Loreto für ihre Mitbrüder veranstalten. Vgl. diesbezüglich insbes. die Beschreibung des Itinerariums in Tirocchi, Viaggio da Roma alla Santissima Casa di Loreto, S. 67-87 sowie eine weitere Beschreibung, die sich auf eine nach dem Jubeljahr 1600 veranstaltete Reise bezieht in BAV, Fond. Cap. 82, f. 1r-22v.

717 Ann. Ecc., I, a. 34, S. 183-185. Baronio bezieht sich diesbezüglich auf die Stelle aus der Historia Ecclesiastica des Nikephoros Kallistou Xanthopoulos. Vgl. hierzu PG, Bd. 145, Sp. 726-730. Zur Verbreitung des ab 1553 ins Lateinische übersetzten Werks vgl. Gastgeber 2009, S. 237-247. Flacius selbst bezog sich in seinem Catalogus testium veritatis, S. 930bis-931bis auf die drei Jahre zuvor in Basel bei Johannes Oponorius gedruckte lateinische Übersetzung: [...] prolixe narrat olim varias 
Ein solches officium der Pflege des Grabes Christi, das gleichsam als Pflege des Aufbewahrungsortes der Hostie im Sakramentstabernakel verstanden wurde, betonte den innigen Zusammenhang zwischen dem Sakrament der Eucharistie und den Reliquien der Kreuzigung. Die heilsspendende Kraft dieses Sakramentes schöpfte sich demzufolge aus der ursprünglichen Nähe des Leibes Christi zu den instrumenta des Kreuzes- und Messopfertodes in der aus Stein errichteten Grablege. Das Jubeljahr 1575 musste daher mit diesem auf die indulgentiae fokussierten Kurienzeremoniell, mit welchem sich der göttliche Heilserlass über den Kirchenschatz auf die Gläubigen ausbreiten liess, eine besondere Nachfrage in der Ausgestaltung liturgischer officia hervorgerufen haben. Diese rituellen Ausgestaltungen der Liturgie brachten eine Wechselwirkung zwischen dem unsichtbar in allen Sakramenten überführten Leib und der sichtbar enthüllten Reliquienüberlieferung zum Vorschein. Allein in der Reliquiennähe des beerdigten Leibes konnte überhaupt die in der Eucharistie enthaltene Gnadenkraft den Gläubigen liturgisch vermittelt werden. Die seit der Kreuzigung überlieferten Reliquien ebneten daher einen für das Kurienzeremoniell geeigneten Weg, um über alle Sakramente hinweg die Heilserfüllung im römischen Stadtraum verwirklichen zu können. Diese sakramentale Verwaltung des Heilsversprechens Christi nach dem Kreuzes- und Messopfertod begann sich vor allem in der künstlerischen Ausgestaltung des Palazzo Apostolico zu verwirklichen. Die neue Bildprogrammatik im Apostolischen Palast nahm in gewisser Weise eine im Zusammenhang mit der sakramentalen Verwaltungspraxis noch zu schreibende historia ecclesiastica bereits vorweg.

fuisse consuetudines et ritus ecclesiarum circa festa, ieunia, cibos vetitos, ecclesiasticas caeremonias [...] Ubi clare videtur perstingere papam eiusque spirituales, qui per suas humanas tradiunculas mandata Dei antiquant et obliterant. Quis enim ignorat in papatu longe maius peccatum haberi comendere die Veneris autin Quadragesima carnes quam furari, defraudare suum proximum aut scortari. 